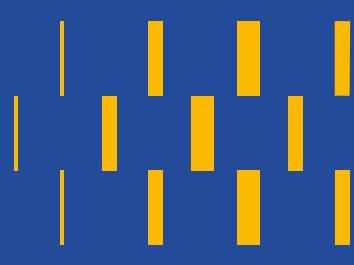

\title{
Arqueología republicana en Antofagasta de la Sierra, puna de Atacama: un abordaje desde los espacios internodales y espacios domésticos
}

\section{Republican Archaeology in Antofagasta de la Sierra, Puna de Atacama: an approach from the internodal and domestic spaces}

\author{
M. Soledad Martinez ${ }^{1}$ (D) https://orcid.org/0000-0003-2922-7981 \\ Diego Zamora2 (D) https://orcid.org/0000-0003-3593-3225 \\ ${ }^{1}$ Instituto Superior de Estudios Sociales (ISES), Consejo Nacional de Investigaciones Científicas y Técnicas \\ (CONICET). ARGENTINA. Email: solemartinez216@hotmail.com \\ ${ }^{2}$ Instituto Superior de Estudios Sociales (ISES), Consejo Nacional de Investigaciones Científicas y Técnicas \\ (CONICET).ARGENTINA. Email: dzamoranasca@gmail.com
}

\section{Resumen}

En este trabajo abordamos aspectos de la ocupación en la actual puna meridional argentina (puna de Atacama) durante el Período Republicano (siglos XIX y XX) a través de casos de estudio arqueológicos de Antofagasta de la Sierra y El Peñón. Exponemos una de las múltiples formas de habitar el territorio por parte de las poblaciones puneñas durante la conformación y consolidación del Estado-nación, abordando ciertas prácticas de consumo en dos dimensiones espaciales: 1. la doméstica, representada en una estancia vinculada al poblado de Antofagasta de la Sierra, y 2. las comprendidas por las áreas internodales, o los espacios "vacíos" en los que se daba la circulación, la trashumancia y otras actividades.

A partir de nuestros casos de análisis, discutimos en particular cuestiones vinculadas a la incidencia del Estado-nación en el modo de vida puneño -en relación a las prácticas cotidianas, el pastoralismo trashumante y la realización de viajes a larga distancia- sus continuidades y discontinuidades, adopciones y resistencias desde otras ontologías que nos alejen de las dicotomías cartesianas tradicionales, de manera de abordar el vínculo entre nociones tales como memoria, paisaje, territorialidad y movilidad en el área puneña.

Palabras clave: arqueología republicana, estudios internodales, espacios domésticos, puna de Atacama. 


\begin{abstract}
In this paper we present the results of archaeological research focused on the Republican Period (XIX and XX centuries) in Antofagasta de la Sierra, in the actual Argentinian southern Puna (the Atacama Puna). We are going to expose the ways of inhabit the territory by the Puna population during the rising and consolidation of the State, taking into account practices of consumption in two spatial dimensions: 1 . The domestic one, represented by an "estancia" -a rural house or farmstead, linked to the town of Antofagasta de la Sierra, and 2. The internodal areas, or the "empty spaces" in which the circulation, traffic and other activities were done.

We will particularly discuss issues related to the puneño way of life -related to daily activities, migratory herding, and long distance travelling, their continuities and discontinuities, adoptions and resistances from ontologies that move us away from traditional Cartesian dichotomies, in such a way to link notions such as memory, landscape, territory and mobility in the Puna area.
\end{abstract}

Keywords: republican archaeology, internodal studies, domestic spaces, Atacama Puna Region.

Recibido: 28 mayo 2020. Aceptado: 23 noviembre 2020 


\section{Introducción}

La interpretación del registro arqueológico muestra trayectorias históricas con continuidades y cambios en la larga duración en Antofagasta de la Sierra, dentro de la puna de Atacama en el actual territorio de la provincia de Catamarca. Sobre el sector intermedio de las quebradas subsidiarias se encuentran a lo largo del río Las Pitas, afluente del río Punilla, una serie de formaciones rocosas que sirven de soporte a las instalaciones arquitectónicas y aleros rocosos. Estas formaciones representaron el hogar de las poblaciones puneńas desde hace 11000 años atrás y continúan habitadas inclusive hasta la actualidad. Diversas estructuras arquitectónicas y paneles con arte rupestre asentados al pie de las peńas, en las cumbres o sobre los grandes farallones demuestran una extensa historia ocupacional. Esta historia ocupacional de la que hablamos se remonta a tiempos de cazadores recolectores (Aschero 1994, 1999; Martínez 2012, 2014; Pintar 2014), a la transición hacia sociedades que producían alimentos (Babot, 2006; Hocsman 2006, 2007; Aschero y Hocsman, 2011; Hocsman y Babot, 2018) y sociedades agropastoriles que desarrollaron complejas organizaciones (Babot et al., 2006; Martel y Aschero, 2007; Babot et al., 2009; López Campeny, 2009, 2014; Cohen, 2010, 2014; Martel, 2010; González Baroni, 2013, 2014); siglos antes y al momento de la ocupación incaica del Noroeste Argentino (López Campeny y Martel, 2014), para luego formar parte -con sus particularidades- del orden colonial (Quiroga, 2014, 2015; Martinez, 2020a) y del Estado-nación (Martinez 2012, 2017, 2020b; Zamora 2019).

En relación al espacio doméstico en tiempos prehispánicos en el área de estudio, una de las tantas formas de habitar la puna implica una territorialidad que incluye una multiplicidad de parajes, asentamientos y distintas locaciones, propias de una movilidad pastoril. Hablamos de una forma de habitar de pastores y pastoras que si bien pueden tener un asentamiento fijo, incorporan la movilidad en el cotidiano. La casa de los pastores es un tema ampliamente investigado en los Andes desde diferentes disciplinas sociales (Arnold, 1998; Yacobaccio et al., 1998; Flores Ochoa y Kobayashi, 2000; Nielsen, 2000; Göbel, 2002; Delgado y Göbel, 2003; Tomasi, 2012; entre otros). Esta lógica andina de las prácticas y formas de habitar tan dinámica y con tanta flexibilidad es algo que ya se propone en estudios etnográficos (Göbel 2002). Desde la arqueología se ha podido ver muy tempranamente (Yacobaccio et al., 1998); y en la quebrada Las Pitas, desde tiempos prehispánicos (Aschero, 2000; López Campeny, 2001, 2009; Escola, 2002; Cohen, 2005, 2010; Quiroga y Cohen, 2007, entre otros) hasta tiempos coloniales y republicanos (Martinez, 2020a; Martinez y Ataliva, 2020).

Esta concepción de una territorialidad móvil y dispersa en el paisaje también se ve expresada en la realización de viajes a mediana y larga distancia, parte fundamental de la vida puneńa. Estos viajes se evidencian por la presencia de bienes alóctonos en contextos domésticos, rituales y funerarios, así como en el arte rupestre con representaciones caravaneras relacionadas a los mismos, y más recientemente, con la caracterización e identificación de ramales de senderos con estructuras y artefactos relacionados con este tipo de movimientos. Estas investigaciones se realizaron en el marco teórico-metodológico de los estudios internodales, enfocado en la investigación de los espacios "vacíos", las grandes áreas con baja intensidad de ocupación y uso humano, pero que eran el escenario de los viajes a larga distancia, así como de otras actividades económicas, sociales y rituales (Aschero et al., 2002-2004; García et al., 2002; Molina Otárola, 2010; Martel, 2010; Pimentel, 2013; Martel et al., 2017; Nielsen, 2017; Zamora, 2019).

La creación de los Estados republicanos en el Cono Sur de América durante el siglo XIX llevó a la fragmentación de espacios que hoy se encuentran repartidos entre Bolivia, Chile y 
Argentina. Las acciones de cada uno de los Estados nacionales estuvieron orientadas tanto a la integración material como a la integración cultural de esos territorios (Benedetti, 2002). A partir del siglo XIX el área de investigación pasó a formar parte del Estado-nación y enfrentó complejas situaciones territoriales y políticas. Antofagasta de la Sierra formaba parte de la puna de Atacama, territorio en disputa por los países limítrofes mencionados. En 1825 deja de pertenecer a la provincia de Catamarca pasando a Bolivia hasta 1879. A partir de esta fecha, es integrada a Chile y recién en 1899 se constituyó como parte del territorio argentino. En el siglo XX (1901) se crea el Territorio Nacional de Los Andes, que comprendió en su extensión a la localidad antofagasteña hasta 1943, año en que esta se integra nuevamente a la provincia de Catamarca (Benedetti, 2005; Kuperszmit, 2009; Martinez, 2012, 2020a-b; Zamora, 2019).

En la conformación del paisaje social las puneñas y puneños trazaron vínculos con su entorno natural de una manera particular, con las peńas de ignimbrita, las vegas, los animales, elementos del paisaje que habitaron en ella y en los caminos trazados a lo largo de sus viajes, para interactuar con poblaciones e intercambiar recursos de otras ecorregiones. Entendemos el paisaje como un medio en constante construcción dialéctica, aprehendido y reproducido por los que lo recorren y habitan. El paisaje atravesado por una red de circulación está conformado así por el espacio físico no antrópico, la percepción física corporal del mismo por parte de los humanos, y el espacio mental cognitivo que se construye con el movimiento, el encuentro y la interacción entre personas y entre personas y entidades no humanas, y el tiempo (Araneda, 2017; Zamora, 2019).

$\mathrm{Al}$ recorrer los caminos, la persona que viaja repite un itinerario configurado como un relato, atravesando espacios y significados que se despliegan frente al observador (Tilley, 1994), espacios que no son en ningún modo abstractos o neutrales o "desiertos", sino historiados y producidos por la vivencia humana (Ananchev, 2012). En las comunidades puneńas, la realización de viajes intra e interregionales, solos y en compañía, funcionaba como una fuerza de producción y reproducción social e identitaria, tramando las redes relacionales entre el individuo y la comunidad, el paisaje y las entidades regentes de estos espacios y actividades (Cruz, 2014). El recorrer los caminos, aprendiendo y reconociendo marcas y significados puede verse como una forma de memoria social materializada en el paisaje (Ricoeur, 2000).

En este sentido el espacio producido socialmente combina así lo cognitivo, lo físico, lo emocional y la memoria, en algo que siempre está abierto a la transformación y al cambio; algo constituido por diferentes densidades de la experiencia humana, el apego y el "involvement" (Tilley 1994).

El propósito de este artículo es discutir ciertas prácticas de consumo y de uso del espacio en tiempos republicanos, identificadas en el área de Antofagasta de la Sierra y sectores adyacentes en dos ámbitos distintivos: 1. los espacios domésticos, centrándonos en la Estancia Peñas Chicas, un domicilio rural que forma parte de la unidad residencial de una familia de pastores y que fue habitada en el período comprendido entre fines del siglo XIX y principios del XX, y 2. los caminos, senderos, campamentos y puestos identificados en las áreas de Peñas Chicas del Peñón, Carachipampa, Los Negros y Paicuqui.

Ahora bien, teniendo en cuenta todo lo expuesto en relación a las formas de habitar por parte de las poblaciones puneñas desde los espacios domésticos e internodales en tiempos prehispánicos, nos proponemos discutir la incidencia concreta de los nuevos Estados-nación, "marcando" límites territoriales y nuevas normativas en la vida de las familias y la comunidad puneña durante los siglos XIX y XX. Proponemos que las trayectorias históricas de una lógica territorial pastoril y trashumante persisten (sensu Silliman, 2009) todavía en contextos de modernidad. 


\section{Contexto ambiental}

La puna es una planicie ubicada por encima de los $3000 \mathrm{msnm}$ en el extremo noroeste de Argentina. Abarca parte de las actuales provincias de Salta, Jujuy y Catamarca. Su límite norte está conformado por los cerros Zapaleri y la cordillera del volcán Vilama. Hacia el este se extiende hasta la Sierra de Santa Victoria, los nevados de Cachi y Chañi, la sierra de Quilmes o el Cajón, y la cordillera de Buenaventura. Hacia el oeste, el límite político actual está marcado por la frontera con Chile y con las altas cumbres de la cordillera de los Andes. El límite sur está demarcado por la cordillera de Buenaventura. Por el límite este de la puna acceden una serie de valles y quebradas que sirvieron como vías de circulación humana (Reboratti, 2005).

Climáticamente, tomando la región de la puna en conjunto, puede observarse un descenso en las precipitaciones anuales en dirección norte-sur. En la Quiaca se registran precipitaciones anuales medias de $350 \mathrm{~mm}$, mientras que en la puna catamarqueña ha habido años sin precipitación alguna.

Esta diferencia se ve reflejada en los salares que caracterizan la parte sur, denominada puna Salada para diferenciarla de la puna Seca septentrional, de mayores precipitaciones y algunas diferencias ambientales (Santoro y Núñez, 1987). Las escasas precipitaciones y el agua proveniente de las vegas de la vertiente oriental (alimentadas por las nubes, los deshielos y las lluvias en las altas cumbres) se vierten en cuencas endorreicas que desembocan en lagunas en las áreas más bajas, las que tienden a desecarse dando lugar a extensos salares (Olaroz, Hombre Muerto) que resultan de la acumulación de elementos químicos lavados en los faldeos y arrastrados hacia el fondo de las cuencas (Reboratti, 2005).

A pesar de la ubicación subtropical, la altura y la humedad atmosférica baja generan una alta amplitud térmica, con un promedio anual de $10^{\circ} \mathrm{C}$. En meses de verano puede haber diferencias térmicas entre el día y la noche de más de $25^{\circ} \mathrm{C}$ (Reboratti, 2005). El área de Antofagasta de la Sierra se localiza en la porción norte de la provincia de Catamarca, dentro del sector meridional de la puna argentina. Los ríos Punilla, Miriguaca y Las Pitas conforman una cuenca endorreica que desemboca en la laguna Antofagasta, conformando vegas y ambientes aptos para el asentamiento humano debido a los recursos estables y concentrados. Las quebradas de Curuto y Paicuqui se encuentran en el piedemonte occidental de la caldera del volcán Galán, y están atravesadas por la vega de Curuto y por el río Punilla, ambos de aguas permanentes. El área de Carachipampa se localiza al sur de Antofagasta de la Sierra; se trata de una extensa planicie endorreica, en la que desembocan los arroyos Pirica y Colorado (ambos de aguas estacionales/esporádicas) en la laguna y salar de Carachipampa. El Peñón es una localidad ubicada sobre la parte baja de la gran vega del río homónimo, que vierte sus aguas en Carachipampa. Peñas Chicas del Peñón es la denominación local de un cono de deyección que desciende de la ladera occidental de la sierra Laguna Blanca, y que sirve de paso al abra de Pasto Ventura (Paoli, 2011) (Figura 1).

Este ambiente no es homogéneo, ya que presenta diferencias ecológicas y topográficas importantes en distancias cortas. Es por estas diferencias que se han distinguido tres sectores microambientales con alta concentración de recursos (Olivera, 1992): fondo de cuenca (entre los 3400 y los $3550 \mathrm{msnm}$ ), sectores intermedios (3550-3900 msnm) y quebradas de altura (3900- 4600 msnm) (Reboratti, 2005; Paoli, 2011). 


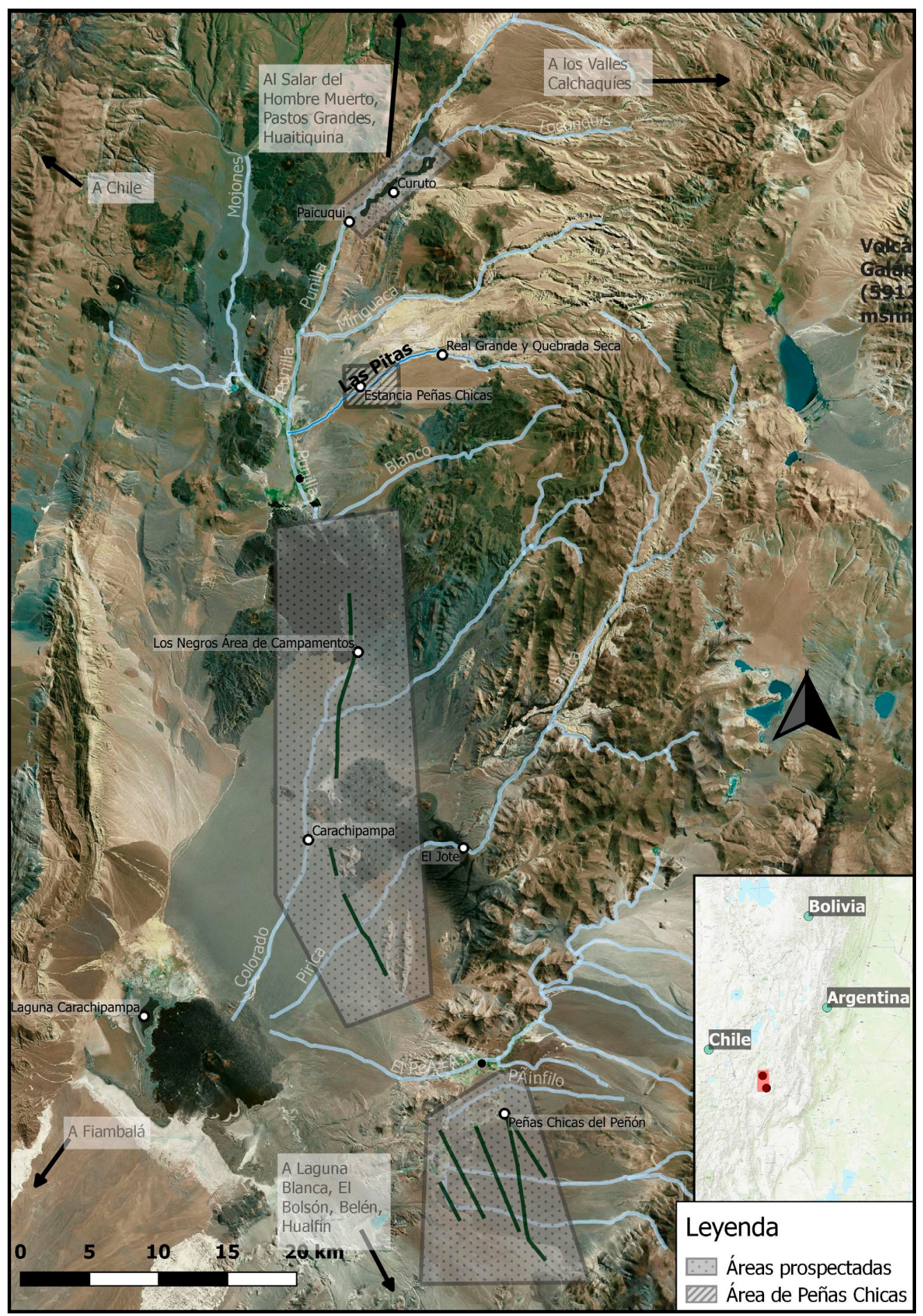

Figura 1. Mapa del área de Antofagasta de la Sierra, El Peñón y la vertiente sudoeste del volcán Galán con las áreas de trabajo destacadas. 


\section{Antofagasta de la Sierra durante el Período Republicano}

\section{Puna de Atacama}

En las últimas décadas del siglo XIX la puna de Atacama se había conformado como una región singular en el contexto de la expansión territorial ocurrida en el espacio cordillerano (Benedetti, 2005). A esa zona se la solía denominar cordillera de Atacama o región este del Desierto de Atacama, y hacia mediados de la década de 1880 comienza a denominarse como puna de Atacama. Desde entonces Argentina, Bolivia y Chile comenzaron a negociar la fijación de límites en la región cordillerana donde se extendían las punas, lo que significó un mayor interés, según el país, por conocer las particularidades regionales y los posibles límites naturales que pudieran justificar la definición del trazado de los límites interestatales (Benedetti, 2005) (Figura 2).

En 1821, Catamarca se había declarado provincia autónoma, tomando su territorio de la jurisdicción acordada en la Real Cédula de 1679 (García y Rolandi, 2003). Sin embargo, en los años sucesivos la zona de Antofagasta de la Sierra cambia de pertenencia. En 1825, dicha localidad, junto con el distrito de Atacama quedan separados de su ámbito histórico y pasan a pertenecer a la recientemente creada República de Bolivia, cuando esta se independiza de las Provincias Unidas. Durante este período, si bien se nombraron autoridades, la presencia estatal en la región fue sumamente débil y constituyó para los gobernantes un área periférica (Kuperszmit, 2009). Al descubrirse entre los años 1860 y 1870 yacimientos de guano, salitre y nuevas menas de minerales, Atacama se convierte en un distrito más interesante y anhelado por parte de Chile (García y Rolandi, 2004).

Como consecuencia de la Guerra del Pacífico, en el año 1879, la región fue ocupada militarmente por Chile. Luego de la finalización de la guerra, Antofagasta de la Sierra siguió ocupada por tropas chilenas hasta el año 1899. Durante dicha ocupación, se asentarán en el pueblo personas de origen chileno, como lo demuestran las actas de matrimonio citadas por García y Rolandi (2003).

En las últimas décadas del siglo XIX Argentina y Chile mantuvieron intensas negociaciones, junto a Bolivia, para definir la situación territorial del ámbito puneño. Estas negociaciones se definieron en 1899, por la "vía diplomática". El litigio en el sector atacameño del límite argentino-chileno se resolvió al cabo de 10 años, cuando Chile desocupa estas tierras, Bolivia renuncia a ellas y la Argentina le da a este último país el área de Tarija. En marzo de 1899, un representante de cada país, José Uriburu por Argentina y Enrique Mac Iver por Chile, junto con el diplomático estadounidense William Buchanan, establecieron por dónde pasaría el límite internacional de esa región. Del territorio en disputa, que tenía una superficie de $75000 \mathrm{~km}^{2}$, fueron anexadas a la Argentina cerca del 85\%, mientras que el resto quedó dentro de Chile. De esta manera se anexó al país el ámbito conocido como "puna de Atacama”, término que perduró en la Argentina por algún tiempo, lo que sería el antecedente territorial directo del Territorio de los Andes (cf. García y Rolandi, 1999; Benedetti, 2005; Kuperszmit, 2009). 


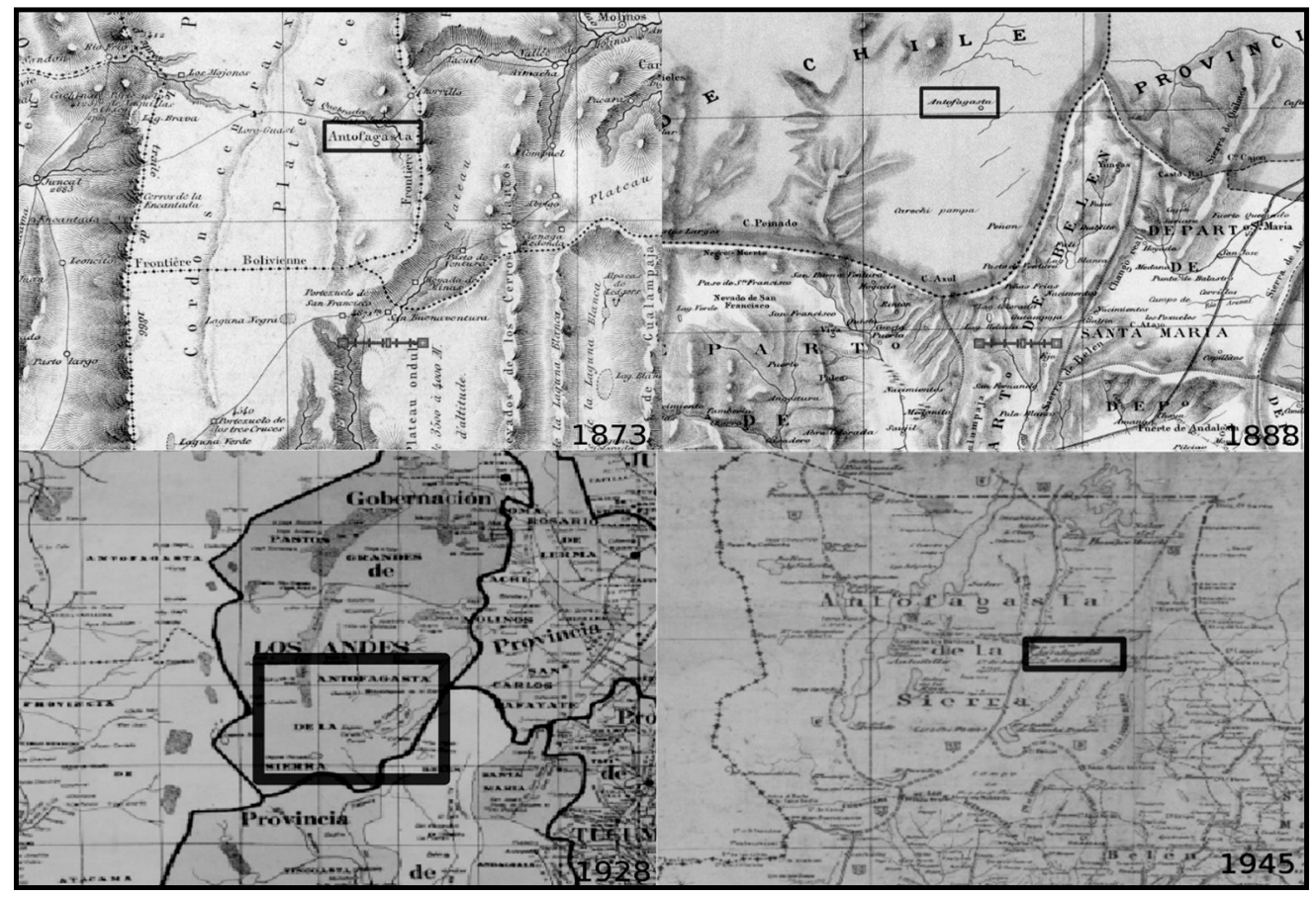

Figura 2. Fragmentos de mapas ilustrando lo mutable de la frontera estatal en el lapso de pocas décadas (De Moussy, 1873; Paz Soldán, 1888, Fragmento de mapa reproducido en Biblioteca Nacional de Espańa, 1928. Administración General de Vialidad Nacional, 1945).

\section{Territorio de los Andes}

Durante la segunda mitad del siglo XIX y parte del siguiente, Antofagasta de la Sierra y otras localidades de la puna participarán activamente como paradas obligadas en los circuitos de arrieros vinculados al comercio de la sal, transporte de minerales y fletes a través de diversas rutas que conectaban los Valles Calchaquíes con, entre otros destinos trasandinos, San Pedro de Atacama, Copiapó, Peine y el puerto de Cobija (Haber, 1999; Conti, 2003, 2006; García y Rolandi, 2003; Molina Otárola, 2010; Sanhueza, 2011; Araneda, 2017; Zamora, 2019).

A partir de 1899, Antofagasta de la Sierra volvió a formar parte del territorio argentino. Con la política de expansión y anexión de tierras surgieron, en la segunda mitad del siglo XIX, los territorios nacionales a partir de la implementación de la Ley 1532 de Organización de los Territorios Nacionales (1884). Esta era una respuesta al problema de la incorporación definitiva y de la regularización de vastas extensiones al norte y sur de la República Argentina, las cuales no estaban comprendidas dentro de los límites de las provincias entonces existentes. No eran entidades políticas autónomas, sino divisiones administrativas dependientes del gobierno central.

El 9 de enero 1900 se produjo la incorporación del Territorio Nacional de los Andes, cuando el Congreso Argentino sancionó la Ley 3906, que estableció formalmente su organización. Entre sus tierras se encontraba la localidad antofagasteńa (Figura 3). En 1943 el Territorio de los Andes se disolvió y cada uno de los poblados se dividió en varias provincias argentinas. Susques se anexó a la provincia de Jujuy, San Antonio de los Cobres y Pastos Grandes a la provincia de Salta y Antofagasta de la Sierra a la actual provincia de Catamarca. 


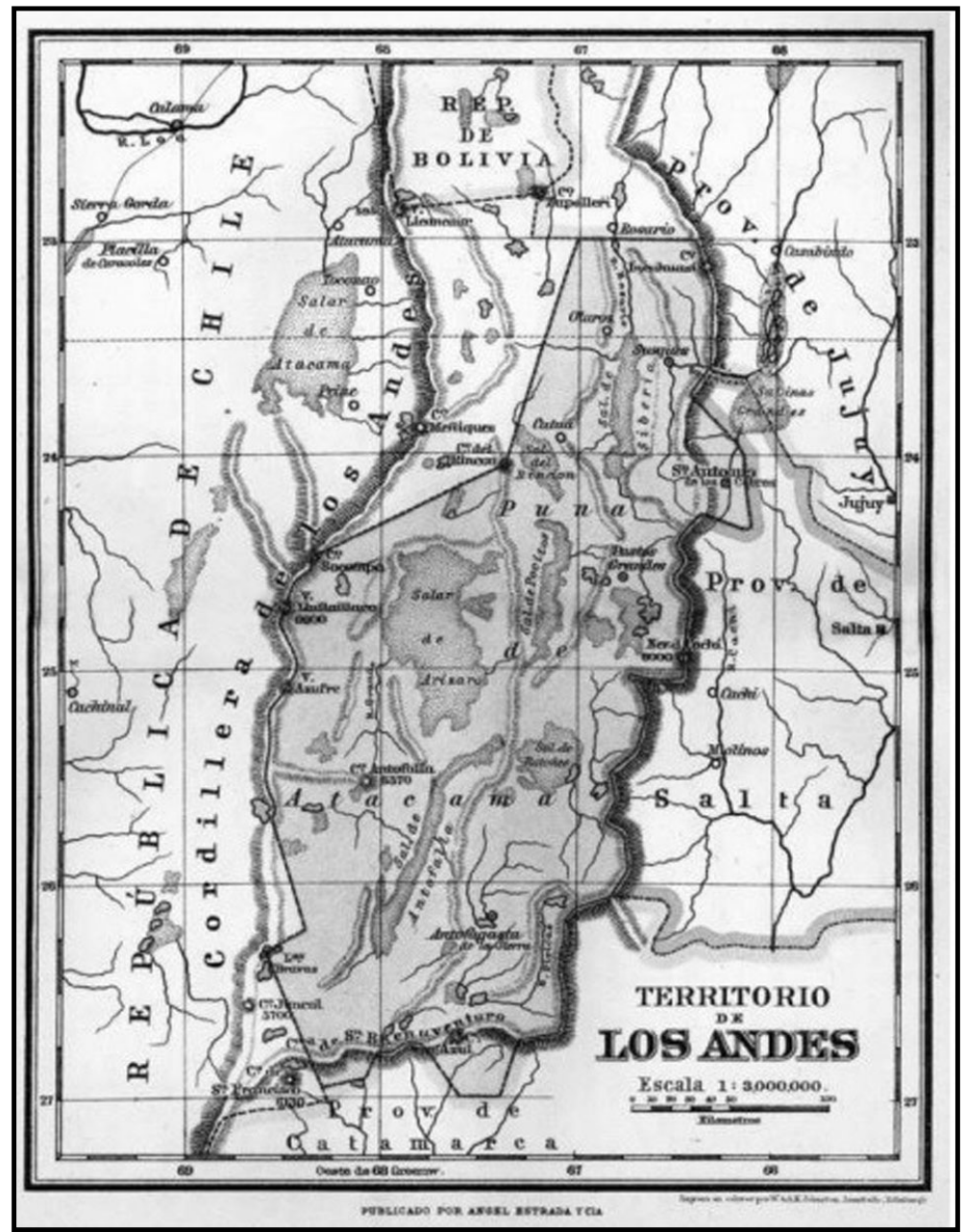

Figura 3. Mapa del Territorio de los Andes (Boero, 1916, cit. en Benedetti, 2005, p. 317).

\section{Investigaciones arqueológicas referidas al Período Republicano en Antofagasta de la Sierra y áreas internodales relacionadas}

La evidencia de las poblaciones puneñas habitando la quebrada del río Las Pitas durante el Período Republicano ha sido poco estudiada hasta el momento. Sin embargo, es significativa y diversa, comprendiendo desde materialidades vinculadas a la ritualidad (Martinez, 2017; Cohen y Martínez, 2020) a viajes y prácticas pastoriles trashumantes (Zamora, 2019) y a unidades residenciales (Martinez y Ataliva, 2020; Martinez, 2020a) en los sectores intermedios (Figura 4).

Peñas Coloradas 3 cumbre y Piedra Horadada 2 son dos sitios que evidencian ocupaciones prehispánicas y cuyos componentes históricos se vinculan a la ritualidad (Urquiza et al., 2013; Cohen, 2014; López Campeny, 2014; Martinez, 2017). A su vez, Punta de la Peña 4, cuya historia ocupacional se remonta a las sociedades cazadoras recolectoras, ha sido reutilizado en tiempos históricos como corral de fauna autóctona domesticada y fauna introducida por los europeos (Urquiza y Aschero, 2014) (Tabla 1). 
En Peñas Coloradas 3 cumbre, de un total de 20 estructuras arquitectónicas -de diferentes modalidades constructivas- emplazadas en la cumbre de la peña de ignimbrita, en cuatro de ellas se obtuvieron fechados radiocarbónicos que muestran historias de ocupaciones coloniales y republicanas, además de prehispánicas, lo cual permitió inferir la reocupación de estructuras prehispánicas en tiempos posteriores. Nos detendremos en las estructuras abovedadas vinculadas al Período Republicano. En la estructura XIII de falsa bóveda, se realizó una datación sobre un fragmento de cestería plana (Martinez, 2012), dando una cronología de 194ะ38 AP (Cohen, 2014; Martinez, 2017). A su vez, se encuentran las estructuras XI y V, ambas de tipo cista subterránea. En la primera de ellas se dató un cordel de fibra vegetal dando $163 \pm 32 \mathrm{AP}$ (AA89400207V) (Cohen, 2014; Martinez, 2017), y en la última, un fragmento de endocarpo de algarrobo que arrojó 128 32 AP (AA89401M189V) (Cohen, 2014). Las estructuras abovedadas se asociaron a prácticas de depósito que abarcaron desde materias primas (vellones, cordeles, minerales); herramientas (agujas, torteros, artefactos líticos, piezas cerámicas, bolsas de tejidos vegetales, entre otros); alimentos (partes animales, endocarpos de Prosopis nigra, $P$. alba y $P$. sp. ) y objetos que pudieron formar parte de ofrendas y/o ajuares funerarios (torteros, vincha de cestería, paquetes y atados rituales) (Cohen, 2010; Martinez, 2012; Cohen, 2014; Cohen y Martinez, 2020b). Desde el análisis de la muestra textil histórica, conformada por cordeles y textiles depositados en las estructuras abovedadas (Martinez 2017, 2020b), interpretamos que allí se resguardaron materialidades textiles con tradiciones tecnológicas preexistentes, pero se incorporaron rasgos distintivos de los nuevos contextos sociohistóricos, mezclando las "antiguas prácticas" con las "nuevas prácticas modernas" resignificando y construyendo una materialidad textil propia (Martinez, 2017).

Piedra Horadada 2 corresponde a un asentamiento a cielo abierto, próximo a la margen sur del río Las Pitas y su cronología se encuentra precisada entre ca. 1900 a 200 años AP (López Campeny, 2009). En la estructura 1 se realizó el hallazgo de un depósito intencional de objetos correspondiente al período de ocupación más reciente del sitio, con una cronología comprendida entre ca. 700 a 200 ańos AP. Este se caracteriza por presentar en su interior un bloque rocoso de gran tamańo y peso (monolito), sostenido en su base por un conjunto de rocas que conforman un cimiento; sumando a esto las características arquitectónicas, estratigráfica y contextual es que se plantea como un recinto asociado a prácticas rituales vinculadas a monolitos-huancas, las que involucran a poblaciones pastoriles hasta momentos posteriores al contacto hispanoindígena (López Campeny, 2009; Urquiza et al., 2013), y en los que los textiles también desempeñaron un rol importante de carácter simbólico ritual (López Campeny, 2014).

Punta de la Peńa 4 es un alero residencial (Hocsman, 2006) que ofrece un reparo de $93 \mathrm{~m}^{2}$ en dos sectores: uno superior y otro inferior con suelo arenoso, ambos con arte rupestre pintado y grabado de distintos períodos y estilos (Aschero, 2005). Presenta una secuencia ocupacional muy amplia, los fechados radiocarbónicos indican presencia humana desde el Holoceno Temprano (ca. 8900 a ca. 8300 años AP); en el Holoceno Tardío (ca. 4500 a ca. 3200 años AP) continuando hacia el $1000 \mathrm{AP}$ y hasta el $500 \mathrm{AP}$ (s. XVI) (Urquiza y Aschero, 2014). Las últimas ocupaciones en el alero PP4 se dan durante el período histórico. La capa 0 está constituida por arena y presenta, además, una potente capa de guano, relacionada con la reutilización del espacio como corral para animales domésticos autóctonos -Lama glama- y de ganado introducido -Ovis aries y Capra hircus-, cuyo pisoteo produjo la mezcla de materiales de diferentes eventos entre ambas capas. Estos corrales parecen haber sido utilizados estacionalmente, debido a las egagrópilas y coprolitos de cánidos, que indican eventos breves sin ocupación. Se recuperaron también espiguillas de Poáceas, endocarpos abiertos de Prosopis sp., semillas de Amaranthaceae, vainas de Hoffmansegia sp. Estos restos se asociaron a plumas de flamencos 
(Phoenicopterus) (Urquiza y Aschero, 2014). Según los autores, para este momento de ocupación es evidente el consumo de guayatas (Chloephaga melanoptera) y ovicápridos. Destacan que de estos últimos se consumieron los cuartos traseros y lomo, sacrificados en torno a los tres años de edad, momento en el que se produce la reposición de la hacienda. Este conjunto de evidencias remite al uso del espacio para el resguardo de animales en momentos posteriores al siglo XVI (Urquiza y Aschero, 2014).

En cuanto a unidades residenciales habitadas solo durante el Periodo Republicano contamos con el caso de Estancia Peńas Chicas, que corresponde a un espacio residencial compuesto por recintos habitacionales y un espacio productivo. La estancia presenta en su interior, sobre el farallón de ignimbrita, grabados históricos interpretados como una práctica de demarcación territorial en un espacio doméstico (Martinez y Ataliva, 2020). Desarrollaremos a lo largo del artículo las prácticas vinculadas a este espacio doméstico.

En el área de estudio se aborda actualmente la problemática del tráfico y movilidad interregional entre un sector de la puna catamarqueña (principalmente, el área que comprende las actuales localidades de Antofagasta de la Sierra y El Peñón) y las áreas valliserrana hacia el este y el sur de este sector puneño. Los trabajos que se vienen realizando desde el año 2011 se ajustan a las propuestas teórico-metodológicas de la arqueología internodal (Berenguer y Pimentel, 2017; Nielsen, 2017), poniendo especial énfasis en el estudio del registro arqueológico generado directamente en la vías de circulación por los artífices del tráfico. En el transcurso de estas investigaciones se identificaron trazas de senderos en gran número y buen estado de conservación. En relación a los senderos, se identificaron numerosas estructuras (de reparo, de uso "ceremonial" y de uso indeterminado), así como un conjunto artefactual que da cuenta de una continuidad en el uso de estos espacios durante el Período Formativo, de Desarrollos Regionales e Inka, como en momentos históricos (botellas de vidrio, latas de conservas, endocarpos de durazno) (Martel, 2014; Martel et al., 2017; Zamora, 2019).

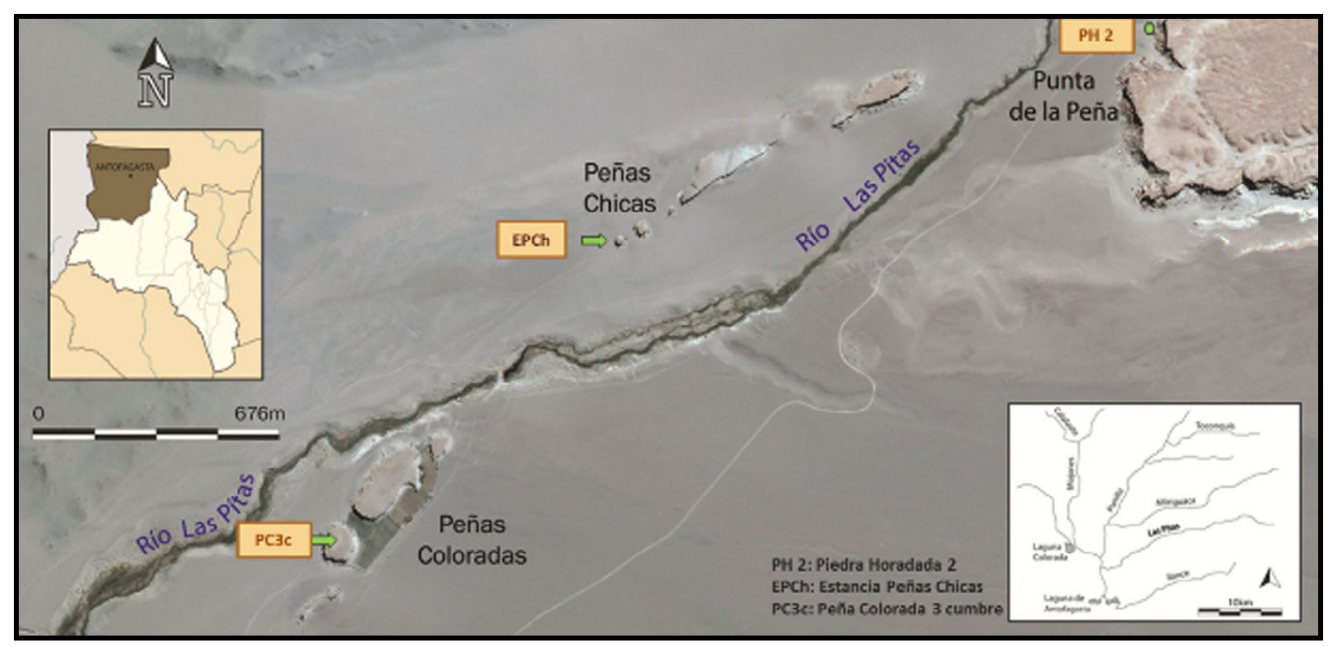

Figura 4. Localización de los diferentes sitios con ocupaciones en momentos históricos en la quebrada del río Las Pitas. 
Tabla 1. Compilación de fechados radiocarbónicos que abarcan el Período Republicano en los sitios próximos a los casos de estudio en los sectores intermedios, quebrada Las Pitas.

\begin{tabular}{|c|c|c|c|c|c|c|}
\hline $\begin{array}{l}\text { Nombre } \\
\text { del sitio }\end{array}$ & Procedencia & $\begin{array}{l}\text { Muestra } \\
\text { datada }\end{array}$ & Fechado AP & Código & $\begin{array}{l}\text { Calibración } \\
2 \text { sigma }\end{array}$ & $\begin{array}{c}\text { Referencia } \\
\text { bibliográ- } \\
\text { fica }\end{array}$ \\
\hline $\begin{array}{l}\text { Piedra } \\
\text { Horadada } \\
2 \text { (PH 2) }\end{array}$ & $\begin{array}{c}\text { Estructura } 1 \\
\text { Capa } 1\end{array}$ & Óseo fauna & $\begin{array}{l}220 \pm 30 \\
\text { años AP }\end{array}$ & CAIS 15100 & $\begin{array}{c}1654-1794 \\
\mathrm{AD}\end{array}$ & $\begin{array}{l}\text { López } \\
\text { Campeny, } \\
2014\end{array}$ \\
\hline $\begin{array}{l}\text { Peñas } \\
\text { Coloradas } \\
3 \text { Cumbre } \\
\text { (PC3c) }\end{array}$ & $\begin{array}{c}\text { Estructura } \\
\text { XIII } \\
\text { Falsa } \\
\text { Bóveda. } \\
\text { Capa 1 }\end{array}$ & $\begin{array}{l}\text { Fragmento } \\
\text { de cestería }\end{array}$ & $\begin{array}{c}194 \pm 38 \text { años } \\
\text { AP }\end{array}$ & $\begin{array}{c}\text { AA89398 } \\
\text { M46R }\end{array}$ & $\begin{array}{c}1720-1820 \\
\text { AD }\end{array}$ & Cohen, 2014 \\
\hline $\begin{array}{l}\text { Peñas } \\
\text { Coloradas } \\
\text { 3-cumbre } \\
\text { (PC3 c) }\end{array}$ & $\begin{array}{c}\text { Estructura } \\
\text { XI } \\
\text { Cista } \\
\text { Pozo }\end{array}$ & $\begin{array}{l}\text { Cordel } \\
\text { vegetal }\end{array}$ & $\begin{array}{c}162 \pm 32 \text { años } \\
\text { AP }\end{array}$ & $\begin{array}{c}\text { AA89400 } \\
207 \mathrm{~V}\end{array}$ & $\begin{array}{c}1720-1890 \\
\mathrm{AD}\end{array}$ & Cohen, 2014 \\
\hline $\begin{array}{l}\text { Peńas } \\
\text { Coloradas } \\
\text { 3-cumbre } \\
\text { (PC3c) }\end{array}$ & $\begin{array}{c}\text { Estructura V } \\
\text { Cista. } \\
\text { Capa } 2\end{array}$ & $\begin{array}{l}\text { Endocarpo } \\
\text { de algarrobo }\end{array}$ & $\begin{array}{c}128 \pm 32 \text { ańos } \\
\text { AP }\end{array}$ & $\begin{array}{l}\text { AA89401 } \\
\text { M189V }\end{array}$ & $\begin{array}{c}1800-1960 \\
\mathrm{AD}\end{array}$ & Cohen, 2014 \\
\hline
\end{tabular}

\section{Espacios Internodales (caminos, senderos, campamentos y puestos) como caso de estudio}

Los estudios internodales entienden el espacio como una red de nodos -áreas de cruzamiento o vértices de una red de interacción (Haggett, 1976; Nielsen, 2006)-, conectados con espacios internodales o internodos. Un nodo, en el caso puntual en estudio, sería un espacio con una ocupación humana permanente o semipermanente que corresponde en esta investigación al poblado de Antofagasta de la Sierra y sus estancias, en el que se dan actividades productivas y reproductivas y hay un uso relativamente intenso del espacio. Los internodos, por el contrario, son los espacios con muy poca o nula densidad poblacional, en los que las actividades y las ocupaciones son de tipo esporádico y poco intensivo y que son principalmente utilizados como vías de paso. Partiendo de esto último, los caminos y senderos que conectan asentamientos siempre se desarrollan en espacios internodales, por lo que una arqueología de los caminos necesariamente es una arqueología internodal.

Siguiendo esta premisa teórica, Nielsen $(2006,2017)$ propuso como método para abordar arqueológicamente estos espacios la identificación de corredores de tránsito, áreas geográficas que por razones topográficas u otras actúan como embudos o cuellos de botella de las líneas posibles de movimiento humano. La identificación y prospección de estos corredores de tránsito es entonces el primer paso de un abordaje arqueológico de los espacios internodales.

En tres campañas de prospección (2014, 2017 y 2020), se relevó parte de los corredores de: 1. Peñas Chicas del Peñón, una planicie que conecta el abra de Pasto Ventura (que es el paso natural hacia Laguna Blanca y los valles del Bolsón y Hualfín) al sur con el pueblo de El Peńón 
al norte; 2. Carachipampa, una extensa planicie que sirve de conexión entre El Peñón (en su extremo sur), Antofagasta de la Sierra (en su extremo norte) y los valles de Abaucán y Saujil (en su extremo sudoeste), y por último, 3. las quebradas de Paicuqui y Curuto, que representan el primer tramo de uno de los caminos circun-volcán Galán que cruzan el internodo de este para alcanzar los nodos calchaquíes de Colomé y Molinos hacia el este y el salar del Hombre Muerto hacia el noreste.

Durante las prospecciones se identificaron numerosos ramales de senderos, así como estructuras y artefactos asociados a las mismas. Los senderos pueden ser aislados (de una sola huella bien consolidada) o compuestos por múltiples huellas paralelas, formando trazas de hasta $150 \mathrm{~m}$ de ancho. Siguiendo las consideraciones que realizó Pimentel (2013), se observaron senderos de huellas entrecruzadas (atribuibles al tránsito de camélidos) y de huellas paralelas (relacionadas con el movimiento de animales europeos tales como equinos, ovinos y bovinos).

Directamente relacionadas a estos senderos, se identificaron estructuras que pueden separarse en dos grupos generales por su forma y probable función: estructuras de reparo, con muy poca inversión en su construcción y de formas circulares o de media luna y estructuras monticulares. Estas últimas consisten en acumulaciones de rocas de porte grande o mediano, en ocasiones formando estructuras afines al tipo Apacheta (estructura monticular generada por el agregado continuo de rocas y otras ofrendas a lo largo del tiempo), así como otras de menor porte que evidencian haber sido construidas en un solo evento (Zamora, 2019). Paralelamente a nuestro trabajo, Patané Aráoz (2018) identificó ramales y estructuras de reparo en el sector sudoeste de la cuenca de Carachipampa, tratándose probablemente de los senderos que conducían al valle de Fiambalá.

En el sector norte del área prospectada en Carachipampa se encuentra la colada volcánica de Los Negros, la cual interrumpe el tránsito por los senderos canalizándolos en una quebrada estrecha ubicada en el sector este de la misma. En un espacio reparado de la colada volcánica se identificó también un área de campamentos, caracterizada por acumulaciones dispersas de artefactos de lata, vidrio y óseos y escasa o nula inversión constructiva. Este sitio se considerará como un sector de prospección independiente, aún perteneciendo a la órbita del corredor Carachipampa, debido a la concentración de materiales y rasgos significativos.

\section{Espacios domésticos: Estancia Peńas Chicas como caso de estudio}

La Estancia Peñas Chicas se ubica a $200 \mathrm{~m}$ sobre la margen norte del curso medio-inferior del río Las Pitas, a 3543 msnm (coordenadas geográficas: 260158” S y 67²13” W), a 5 km al norte de la localidad actual de Antofagasta de la Sierra. Se emplaza lindante a una peña de ignimbrita de $12 \mathrm{~m}$ de altura, a lo largo del farallón este. Las estructuras arquitectónicas han sido construidas de norte a sur, adosadas a la peña, alcanzando una longitud de $25 \mathrm{~m}$. La familia de pastores/as que residió en el lugar aprovechó el sector de la Peña que presenta una cara plana posibilitando la edificación, resguardándose de los fuertes vientos (Martinez, 2020a) (Figura 5).

En la estancia confluyen espacios residenciales y productivos, principalmente con asiento en las prácticas pecuarias. Sus instalaciones remiten a la economía familiar y a su empleo estacional. Durante el lapso que estuvo habitada (desde fines del siglo XIX hasta la década del treinta del siglo XX), la estancia fue incorporada a un circuito familiar que incluía el "domicilio grande" 
en Falda de Ilanco, a unos $7 \mathrm{~km}$ al sureste, donde se encontraba el "caserío más importante", y en el que se residía parte del año. Los meses más cálidos (octubre hasta abril-mayo) se trasladaban a Peñas Chicas, desde donde los niños asistían a la escuela del pueblo. Las mejores pasturas y abundante agua se hallaban en este sector. El "domicilio grande” y la estancia constituían las cabeceras de un circuito que incluía también otros corrales y puestos (Martinez y Ataliva, 2020).

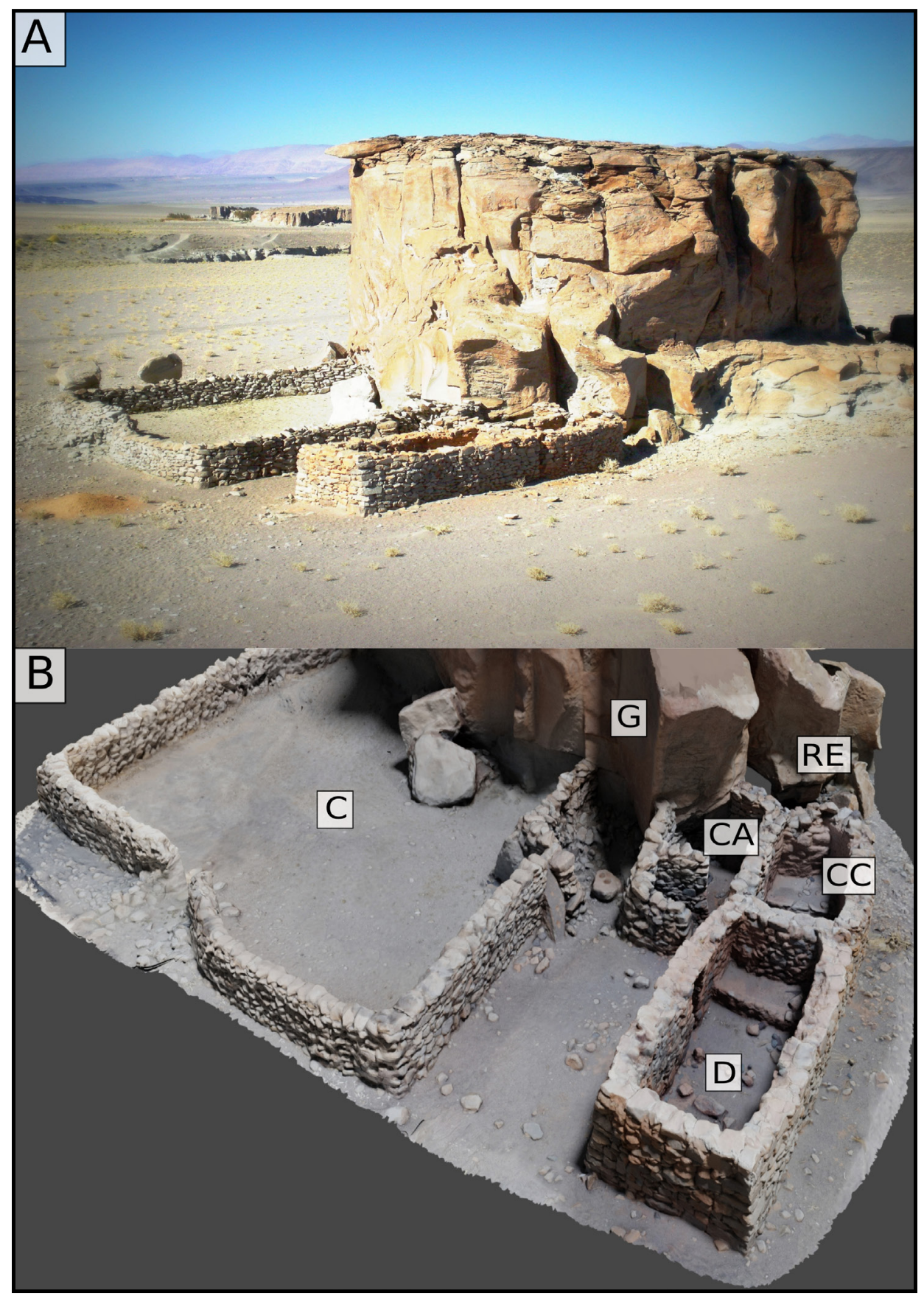

Figura 5. A) Estancia Peńas Chicas vista desde el noreste, B) Los espacios que constituyen la estancia, C) Corral, G) Grabados, CA) cocina abierta, RE) recinto externo, CC) cocina cerrada, y D) dormitorio. 
Los recintos arquitectónicos fueron construidos con roca ignimbrítica, es decir, con materia prima propia del entorno cercano. La arquitectura en superficie presenta una altura que oscila de $1 \mathrm{~m}$ a $1,50 \mathrm{~m}$. Se registró una porción del techo incinerado y desmoronado sobre uno de los recintos. No posee ventanas, sí dos puertas y hornacinas en dos de sus recintos contiguos. A partir de la entrevista a don Vicente Morales, un pastor que vivió allí con su familia durante las primeras décadas del siglo XX, se pudieron identificar, desde la oralidad, la funcionalidad de los diferentes espacios arquitectónicos. Así, la estancia presenta una combinación de unidades residenciales definidas por el dormitorio, la cocina cerrada, la cocina abierta y otros dos recintos donde se desarrollaban actividades de producción de hilado, por un lado, y una unidad productiva correspondiente al corral rectangular de grandes dimensiones (de $15 \times 9 \mathrm{~m}$ ), por otro lado. Dicho recinto pecuario se encuentra separado por un pasillo de 3,5 m de amplitud de los recintos habitacionales antes mencionados y un sector de grabados históricos sobre el farallón de la peña (Martinez, 2020a).

Esto último es una característica distintiva del sitio; las manifestaciones en sus paredes de representaciones rupestres han sido definidas como monogramas, grabados que remiten a nombres, apellidos, y fechas que permitieron abordar relaciones de poder inter e intracomunitarias protagonizadas por los puneños y el Estado hacia inicios del siglo XX. Es importante destacar que entre los grabados presentes que refieren a instituciones republicanas también se observan, en el mismo panel, representaciones de una caravana de camélidos que fuera realizada por un miembro de la familia de pastores, y las iniciales de sus padres (Martinez y Ataliva, 2020).

Se realizaron excavaciones sistemáticas en los recintos denominados cocina cerrada, cocina abierta, dormitorio y recinto externo. La historia ocupacional de la estancia según la secuencia estratigráfica y el análisis de los contextos de los diferentes recintos nos muestra que una primera ocupación se da en la cocina abierta contemporánea a la construcción del corral. Corresponde a un fueguero (cf. Carreras, 2017) que pudo haber sido utilizado cuando se cuidaba de los animales. Posteriormente, se construyen los otros recintos habitacionales, donde se levanta un muro de cierre en la cocina abierta separando el recinto externo de la misma. La ocupación de la familia en las distintas unidades residenciales se asocia a la construcción del piso de arcilla. Un hallazgo singular se registró en la cocina cerrada, donde se infiere un evento de fundación de la casa en el extremo noroeste del recinto con el enterratorio de un neonato de llama (Lama glama) de entre tres y seis meses, asociado a cordeles de torsión zurda dispuestos alrededor de una roca, algo muy bien documentado para otros sectores del mundo andino por Denise Arnold $(1998,2000)$ y para la puna jujeña, en Susques, por Tomasi (2012).

\section{Evidencia material vinculada a los espacios internodales bajo estudio}

En los cuatro "corredores de tráfico", los rasgos, estructuras y artefactos identificados se registraron fotográficamente, se georreferenciaron y en el caso de los últimos, se recolectaron en su totalidad los identificados a primera vista como de origen industrial e histórico (vidrios, latas y otros artefactos metálicos). Dentro del área de Carachipampa se identificó una subárea en el sector sureste de la colada volcánica de Los Negros (Los Negros Área de Campamentos), dada la mayor densidad de evidencia registrada. El corredor de Paicuqui y Curuto se prospectó siguiendo senderos existentes (previamente identificados en fotos aéreas) y registrando los materiales y estructuras asociados directamente a los mismos. Sobre el Corredor de Peñas Chicas del Peñón no se han recuperado hasta el presente evidencias históricas. Se incluyó asimismo en 
el análisis de materiales un pequeño conjunto de materiales textiles recuperados en un puesto histórico perteneciente al Sr. Melitón Ramos, ubicado dentro de un área prospectada en el sector del río Los Patos, en la vertiente noreste del volcán Galán. En esta área se identificaron estructuras relacionadas al tráfico (reparos, parapetos, arte rupestre), pero aún no se han relevado trazas de senderos o caminos.

En las prospecciones se recuperó un total de 34 artefactos: 8 botellas de vidrio, 19 latas de conserva, 2 herraduras, un cencerro fabricado con una lata de conserva, un fragmento de herradura y 4 piezas textiles (Tabla 2).

En cuanto a las botellas de vidrio, dos se recuperaron sobre un ramal de senderos del corredor de Carachipampa, una de ellas de manera aislada sobre el sendero y la otra en relación a una apacheta o piedra parada (Figura 6). Las seis restantes se recuperaron de un área que nombramos Los Negros-Área de Campamentos (LNAC), un sector de la colada volcánica de Los Negros que fue utilizado como área de pernocte o descanso aprovechando el reparo ofrecido por las rocas volcánicas. Esta área de campamentos se caracteriza por la presencia de materiales históricos dispersos, por lo general acumulados en reparos naturales en la lava. La investigación y análisis de este sitio sigue en curso.

Respecto a las latas de conserva, se recuperaron dos sobre los senderos en el corredor de Carachipampa, 14 en LNAC, y tres sobre los senderos en el corredor Paicuqui Curuto (Figura 6).

Este conjunto material se analizó enfocándonos en el método de construcción y por lo tanto de llenado de las latas. Las tecnologías de enlatado se sucedieron en el siguiente orden cronológico: 1. Latas con uniones soldadas (1810-1880+-), 2. Latas Hole in top y Hole in cap, primero soldadas y luego plegadas y soldadas (1850 +- 1900+-) 3. Latas sanitarias (1898-presente). Debido a que estas tecnologías se solaparon en poco tiempo, y prácticamente en todos los casos las técnicas más modernas reemplazaron inmediatamente a las más antiguas, se consideró este análisis tecno-cronológico como un método apropiado para asignar temporalidades relativas (Rock, 1993; Memmott, 2015). También se consideraron como variables para el análisis la forma general de la lata, el posible uso que esta hubiera tenido, y la presencia o no de inscripciones, fechas de envasado, etiquetas y otras marcas identificatorias.

Se identificaron tres piezas de las 21 como probablemente fabricadas y consumidas a mediados/finales del siglo XIX, a juzgar por la tecnología constructiva, la más temprana de ellas construida con láminas metálicas estampadas y unidas con soldadura de plomo manual. Las 18 latas restantes son del siglo XX; se pudieron identificar dos como relativamente recientes (años de la década del setenta u ochenta), debido a la presencia de etiquetas visibles.

De las piezas textiles, una se recuperó sobre un sendero en el corredor Paicuqui-Curuto y las tres restantes, en la cercanía del puesto del Sr. Melitón Ramos, ubicado cerca del río Los Patos en la vertiente noreste del volcán Galán. La primera consiste en una cuerda de atalaje de fibra natural animal sin tinción (25Y8/4 28). Se analizó microscópicamente la estructura de la fibra, y por la conformación de la cutícula se estima que se trata de lana de llama (Lama glama) doble capa. Estructuralmente, consta de tres cuerdas de hilado simple y torsión Z, las cuales se retorcieron (S) formando un grueso cabo (de $4 \mathrm{~cm}$ de diámetro) atado con un nudo ciego, de manera de constituir un círculo. Este cabo está fragmentado, por lo que la estructura pierde tensión y permite apreciar en algunos sectores los tres elementos que lo componen. Probablemente, el cabo haya sido utilizado para la sujeción de cargas a animales durante los viajes. 
La retorsión derecha de los tres cabos de torsión zurda habría producido un cabo grueso y resistente, ideal para soportar tracciones fuertes. Los cabos componentes se cortaron en dos secciones, desintegrando el cabo grueso, por lo tanto perdiéndose su función original. Dentro del conjunto textil recuperado en el Puesto, se registró otra cuerda de menores dimensiones, de fibra natural de origen animal sin teñir. Presenta torcionado final $\mathrm{Z}$ y dos nudos en los extremos; probablemente era utilizada para "manear" (atar las patas de los animales para inmovilizarlos).

En el mismo sitio se recolectaron dos artefactos construidos con las botamangas de dos pantalones de manufactura industrial, uno de corduroy o corderoy y un "track suit" deportivo (prendas deportivas muy utilizadas en las décadas del setenta, ochenta y noventa, de materiales sintéticos y color azul oscuro). Las dos piezas están elaboradas de la misma forma: la costura interna se corta, conformando una pieza textil de forma aproximadamente trapezoidal. Se practicaron orificios en el perímetro de la pieza, así como en hileras paralelas a lo ancho de la misma, y se conservan fragmentos de hilos aparentemente de fibra animal enhebrados en estas series de orificios. Nuestra hipótesis es que se trata de artefactos pensados para envolver, proteger o para ser utilizados como bolsas contenedoras.

Tabla 2. Evidencia material de cronología republicana vinculada a los espacios internodales.

\begin{tabular}{|c|c|c|c|c|c|c|}
\hline \multirow{3}{*}{$\begin{array}{l}\text { Evidencia } \\
\text { material }\end{array}$} & \multicolumn{6}{|c|}{ Corredores de Tránsito Prospectados } \\
\hline & $\begin{array}{c}\text { Peńas Chicas } \\
\text { del Peńón }\end{array}$ & Carachipampa & $\begin{array}{l}\text { Los Negros- } \\
\text { Area de } \\
\text { Campamentos }\end{array}$ & $\begin{array}{c}\text { Quebradas } \\
\text { de Paicuqui y } \\
\text { Curuto }\end{array}$ & $\begin{array}{l}\text { Puesto M. } \\
\text { Ramos }\end{array}$ & \multirow{2}{*}{$\mathbf{N}$} \\
\hline & $\mathbf{n}=$ & $\mathbf{n}=$ & $\mathbf{n}=$ & $\mathbf{n}=$ & $\mathbf{n}=$ & \\
\hline $\begin{array}{l}\text { Botellas } \\
\text { de Vidrio }\end{array}$ & & 2 & 6 & & & 8 \\
\hline $\begin{array}{l}\text { Latas de } \\
\text { Conserva }\end{array}$ & & 2 & 14 & 3 & & 19 \\
\hline $\begin{array}{l}\text { Otros } \\
\text { arfetactos } \\
\text { metálicos }\end{array}$ & & & & 3 & & 3 \\
\hline Textiles & & & & 1 & 3 & 4 \\
\hline TOTAL & & 4 & 20 & 7 & 3 & 34 \\
\hline & & $12 \%$ & $59 \%$ & $20 \%$ & $9 \%$ & $100 \%$ \\
\hline
\end{tabular}




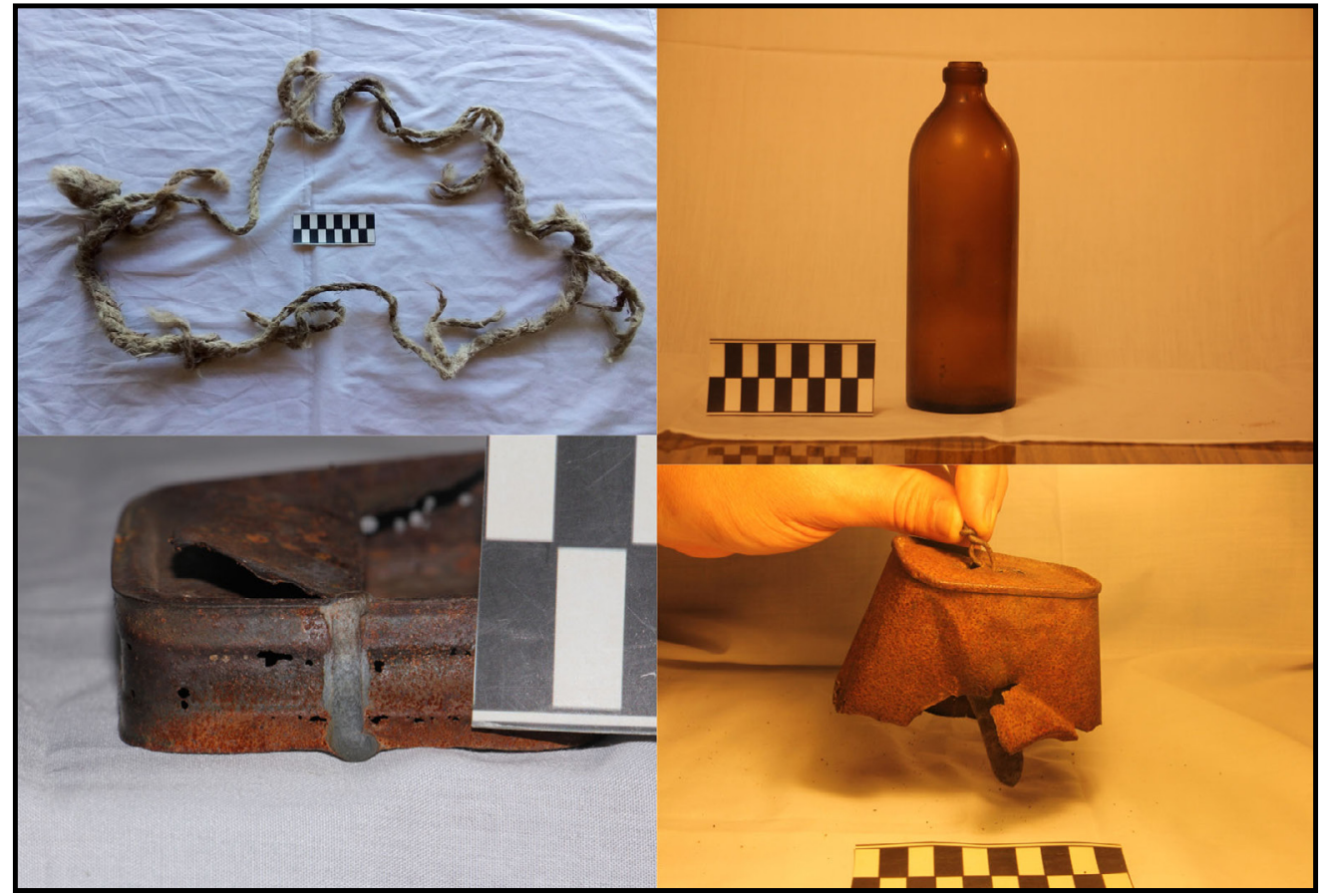

Figura 6. Mosaico de fotos de materiales de cronología republicana recuperados en espacios internodales. De izquierda a derecha y de arriba abajo: Cuerda de fibra animal, botella de vidrio, lata de conserva con detalle de soldadura de plomo, y cencerro fabricado con una lata de conservas, alambre y un fragmento de herradura.

\section{La estancia puneña en tiempos republicanos}

La ocupación de la familia de pastores en los distintos recintos habitacionales de la residencia constituida por la Estancia Peñas Chicas se asocia a la construcción del piso de arcilla y a las diferentes actividades vinculadas a la vida cotidiana y doméstica. Como se desprende de la Tabla 3, la evidencia material en la EPCH es variada y significativa para reconstruir los modos de vivir de una familia puneña en un espacio doméstico a fines del siglo XIX y primeras décadas del siglo XX (Figura 7).

El conjunto de evidencias materiales se compone por elementos que remiten a la cadena productiva textil para consumo familiar como vellones ${ }^{1}(n=71)$, tortero $(n=1)$, cordeles $(n=32)$, plantas tintóreas, restos de una tinaja utilizada posiblemente para teñir, y textiles $(n=39)$, productos tanto del tejido en telar como de la confección con agujas (Martinez, 2020a).

A su vez, el mundo material nos muestra tecnologías originarias como la presencia de restos de cerámica $(\mathrm{n}=36)$ sin marcas de torno alfarero, material lítico $(\mathrm{n}=8)$, restos arqueobotánicos como endocarpos de chañar (Geoffroea decorticans) y algarrobo (Prosopis sp.), restos arqueofaunísticos de camélidos y carbones de plantas leñosas utilizadas como combustible desde el Holoceno Temprano en el área de estudio, como es la Adesmia horrida (Rodríguez 2006). Se trata de bienes que cuentan con una larga tradición de consumo en tiempos prehispánicos en

1 Es importante aclarar que se contabilizaron los vellones por cúmulos, es decir, por un conjunto de vellones entrelazados cuyas dimensiones varían. 
Antofagasta de la Sierra. Asimismo, se recuperaron elementos introducidos después de la colonización europea en la región, como un fragmento de cerámica histórica $(\mathrm{n}=1)$, endocarpos de durazno (Prunus persica), nuez (Juglans regia) y vid (Vitis vinifera), fragmentos de vidrio $(n=2)$, una cuchara de metal $(n=1)$, un clavo chato $(n=1)$, ollas metálicas $(n=2)$, latas $(n=4)$, herradura $(n=1)$, fragmentos de papel $(n=18)$-hojas manuscrita e impresas-y un peine de plástico fragmentado $(\mathrm{n}=1)$.

La preparación y/o consumo de especies vegetales están representados por endocarpos de chañar, algarrobo, durazno, nuez, vid y cucurbitáceas, con un claro predominio en la cocina cerrada $(n=82)$, luego en el recinto externo $(n=53)$, seguido por la cocina abierta $(n=42)$ y por último, con una menor representatividad de los macrorrestos vegetales en el dormitorio $(n=17)$.

En el caso de los restos óseos de animales, se hallaron en mayor proporción en la cocina cerrada ( $\mathrm{n}=99)$ dentro la estructura de combustión o próximos a la misma, a excepción de las mandíbulas de neonato de llama enterradas debajo del piso de arcilla. En el caso del recinto externo, se registró la presencia de restos óseos de fauna $(n=95)$ con alto grado de meteorización expuestos sobre la superficie. En relación a los diferentes tamaños de las partes esqueletales, se infiere que pudieron formar parte de desechos alimentarios del procesamiento y consumo. En la cocina abierta disminuye la representatividad del registro arqueofaunístico $(n=30)$ y en el dormitorio solo se hallaron dos fragmentos óseos: uno corresponde a un astrágalo de Bos taurus (Urquiza, 2018, com. pers.) y el restante, a un cuerpo vertebral.

En relación a la alfarería, las cerámicas reductoras son las predominantes $(\mathrm{n}=33)$ procedentes del recinto externo. Los fragmentos de cerámica de tipo oxidante son lo menos representados $(\mathrm{n}=3)$ y fueron hallados en el dormitorio. No se encontraron restos de cerámica en las dos cocinas, sin embargo, en ellas se hallaron tanto ollas metálicas ubicadas en las hornacinas y próximas al fogón como fragmentos de latas.

En el caso de los recintos denominados como cocina abierta y cocina cerrada, se localizó una estructura de combustión en cada uno de los espacios, las cuales presentan diferencias tanto arquitectónicas como en el consumo de ciertas especies leñosas (Aguirre, 2019). La estructura de combustión ubicada en el centro de la cocina cerrada es superficial y de forma circular, cuya delimitación se realizó con rocas metamórficas e ígneas. La restante corresponde a una estructura cavada cuyos límites se construyeron con rocas metamórficas e ígneas formando un diseño subrectangular adosada a un muro cercano al farallón de ignimbrita; este último fogón presenta un espacio para el ingreso de la leña, donde se identificó una concentración de espículas de carbón. A su vez los restos leñosos identificados en ambas cocinas tienen un gran contenido calórico, junto a otras propiedades como la de ser utilizadas como sahumadoras en la actualidad (Aguirre, 2019).

Registramos un interesante hallazgo en la cocina abierta: se trata de un textil plano 1:1 de fibra animal, fragmentado en varias partes. Asociada al tejido plano de la cocina abierta, próximos al fogón, se hallaron endocarpos de algarrobo, chañar, duraznos y nogal. Esto nos permite retomar lo mencionado por don Vicente Morales en lo expuesto por López Campeny (2009) al narrar los viajes en tropas de burro que realizaban hacia los valles y tierras bajas para intercambiar productos. Relataba el pastor: "Buscábamos leña, maiz, trigo, algarroba [...] la proveeduría que le dicen" y desde aquí transportaban "sal, carne, tejidos, maletas (unas bolsas grandes de lana tejidas en telar, según nos explica). Los viajes podían ser de hasta 15 jornadas o más, dependiendo de las condiciones climáticas" (López Campeny, 2009, p. 81). Estos datos desde la oralidad 
nos permiten articular con los datos del registro arqueológico; es así que proponemos que este tejido de lana, de estructura plana asociado a semillas de otras latitudes, podría corresponder a la evidencia material de aquellos viajes a los que aludía don Vicente Morales: las maletas tejidas en telar (Martinez, 2020a).

Tanto la concentración de cenizas, los restos orgánicos dentro de los fogones -frutos y restos óseos con diferencias en la termoalteración- como la delimitación de áreas de dispersión de sedimento ceniciento y rubefacción en torno a las estructuras de combustión remiten a espacios de cocina.

En cuanto al registro material en el recinto externo, el mayor número de evidencia está representado por el registro arqueofaunístico, seguido por el registro arqueobotánico, los fragmentos cerámicos y los cúmulos de vellones; este conjunto de materiales representa más del $90 \%$ $(n=215)$ del total de evidencia recuperada en el recinto $(n=230)$. Según los datos aportados por uno de los miembros de la familia de pastores, en un primer momento este espacio era utilizado para teñir los hilados, lo que podría vincularse a los restos de tinajas que se hallaron en el recinto externo, asociados a plantas tintóreas en la cocina abierta. Luego de la remodelación arquitectónica, identificada por la construcción del muro que dividió un espacio continuo, se convirtió en una zona de descarte de desechos alimentarios; esto es coherente dado el alto número de ecofactos hallados sobre la superficie.

En el recinto denominado dormitorio, se relevaron tres hornacinas en el muro norte y dos poyos $^{2}$ emplazados sobre los muros este y oeste. En la excavación de la plataforma maciza se halló un fragmento de lienzo que cubría la camada de cortadera (Cortaderia speciosa) dispuesto sobre el poyo. Esta última corresponde a un hallazgo muy particular, ya que las hojas aplanadas se entrelazaban como trama y urdimbre en relación 1:1 para lograr un ajuste con el fin de no desestabilizar la estructura de la camada al no presentar terminación. De esta manera, al cubrir la plataforma maciza se obtenía mayor comodidad y actuaba como aislante térmico, teniendo en cuenta las bajas temperaturas de la región puneña (Martinez, 2020a).

En las excavaciones sistemáticas realizadas en el dormitorio se hallaron elementos vinculados al hilado, tales como un tortero de cerámica reciclado de una pieza prehispánica y un acopio de espinas de Ephedra tramontana, una taba, un peine de plástico fragmentado, y restos de una prenda de vestir confeccionada a partir del tejido en punto. Este conjunto de evidencia material ha sido hallado en un sector particular del dormitorio, contiguo al poyo ubicado al oeste en el interior de una plataforma construida con rocas que resguardaron estos elementos y tejidos de llamativos colores. Es interesante pensar en lo que se eligió preservar, así como un astrágalo de Bos taurus, que corresponde a una "taba", un juego introducido por los espańoles y muy requerido en los ámbitos rurales, y el tortero con procedencia no local, de Bolivia tal vez por sus características estilísticas (Puente, 2018; Martinez, 2020a), lo que nos lleva a pensar en los vínculos que se establecieron luego de "pertenecer" a los países limítrofes durante casi todo el siglo XIX.

2 El poyo constituye un rasgo muy común en la arquitectura andina y cumple distintas funciones; en este caso, se trata de plataformas macizas de ignimbrita y argamasa rojiza y cuyos límites superiores lo conforman unas rocas planas, delgadas tipo lajas, seleccionadas para generar una superficie horizontal (Martinez y Ataliva, 2020). 
Arqueología republicana en Antofagasta de la Sierra, puna de Atacama: un abordaje desde los espacios...

Tabla 3. Evidencia material hallada en contexto de excavación en la Estancia Peńas Chicas.

\begin{tabular}{|c|c|c|c|c|c|}
\hline \multirow{3}{*}{ Evidencia material } & \multicolumn{4}{|c|}{ Recintos excavados de EPCH } & \multirow[b]{3}{*}{$\mathbf{N}$} \\
\hline & $\begin{array}{l}\text { Cocina } \\
\text { cerrada }\end{array}$ & $\begin{array}{r}\text { Cocina } \\
\text { abierta }\end{array}$ & $\begin{array}{l}\text { Recinto } \\
\text { externo }\end{array}$ & Dormitorio & \\
\hline & $\mathbf{n}=$ & $\mathbf{n}=$ & $\mathbf{n}=$ & $\mathbf{n}=$ & \\
\hline Cordeles & 13 & 14 & 1 & 4 & 32 \\
\hline Textiles & 5 & 12 & 9 & 13 & 39 \\
\hline Vellones & 10 & 18 & 24 & 19 & 71 \\
\hline Tortero & - & - & - & 1 & 1 \\
\hline $\begin{array}{l}\text { Fragmentos de } \\
\text { papel }\end{array}$ & 7 & 3 & 4 & 4 & 18 \\
\hline Madera & - & - & 4 & 3 & 7 \\
\hline Cerámica & - & - & 33 & 3 & 36 \\
\hline Restos óseos fauna & 99 & 30 & 95 & 2 & 226 \\
\hline $\begin{array}{l}\text { Muestra de } \\
\text { carbones }\end{array}$ & 321 & 67 & - & - & 388 \\
\hline Herradura & - & - & 1 & - & 1 \\
\hline Latas & 3 & 1 & - & - & 4 \\
\hline Cuchara de metal & - & - & - & 1 & 1 \\
\hline Ollas metálicas & 2 & - & - & - & 2 \\
\hline Cama de paja & - & - & - & 1 & 1 \\
\hline Clavos & 1 & - & - & - & 1 \\
\hline Material lítico & 3 & - & 3 & 2 & 8 \\
\hline $\begin{array}{l}\text { Macrorrestos } \\
\text { arqueobotánicos } \\
\text { (restos leńosos; } \\
\text { endocarpos de } \\
\text { algarrobo, chañar, } \\
\text { durazno, nuez y } \\
\text { vid; cucurbitácea) }\end{array}$ & 82 & 47 & 53 & 17 & 199 \\
\hline $\begin{array}{l}\text { Elementos de } \\
\text { plástico }\end{array}$ & - & - & - & 2 & 2 \\
\hline $\begin{array}{l}\text { Fragmentos de } \\
\text { vidrios }\end{array}$ & - & - & 2 & - & 2 \\
\hline $\begin{array}{l}\text { Fragmento de } \\
\text { cerámica histórica }\end{array}$ & - & - & 1 & - & 1 \\
\hline Total & 546 & 192 & 230 & 72 & 1040 \\
\hline$\%$ & $52,5 \%$ & $18,46 \%$ & $22,12 \%$ & $6,92 \%$ & $100 \%$ \\
\hline
\end{tabular}




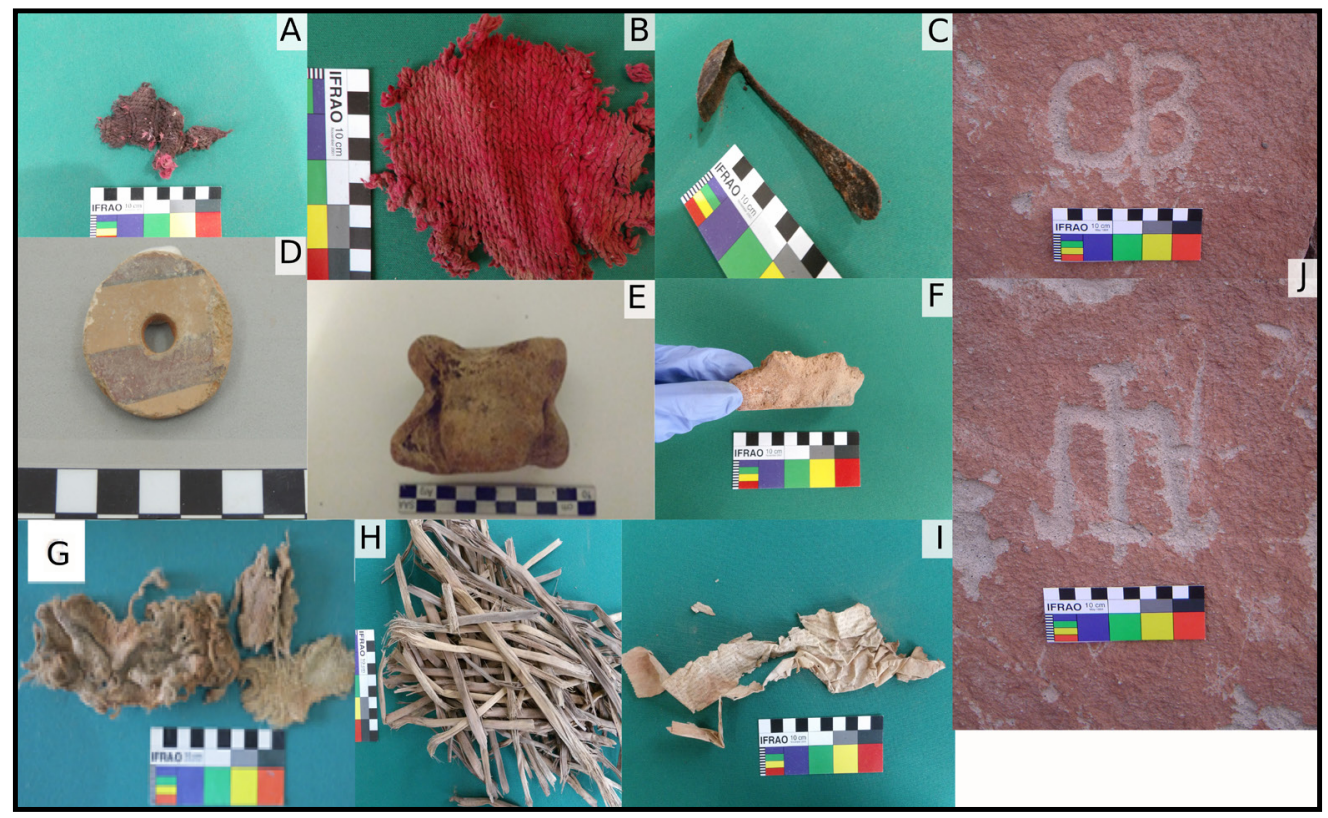

Figura 7. Evidencias materiales halladas en EPCh. A) Fragmentos de tejido teñido realizado en telar; B) Fragmento de prenda de vestir realizada a dos agujas; C) Cuchara de metal; D) Tortero de cerámica; E) Astrágalo de Bos taurus; F) Base de cerámica; G) Fragmentos de maleta tejida en telar; H) Cama de cortadera entrelazada; I) Fragmentos de papel; J) Grabados históricos, iniciales de miembros de la familia que habitó la estancia (Martinez y Ataliva, 2020).

\section{Discusión y consideraciones finales}

A partir del siglo XIX el área de investigación pasó a formar parte del Estado-nación y enfrentó por ello complejas situaciones territoriales y políticas. Las acciones de cada uno de los Estados nacionales estuvieron orientadas tanto a la integración material como a la integración cultural de esos territorios (Benedetti, 2002), situación que fue in crescendo desde finales del siglo XIX hacia el siglo XX, debido a la carrera por asegurar las fronteras en una situación geopolítica muy volátil.

Sin embargo, la incidencia concreta de los nuevos Estados-nación "marcando" límites territoriales y normativas en la vida de las familias y la comunidad puneńa durante los siglos XIX y XX es discutible (Kuperszmit, 2009; Molina Otárola, 2010). Proponemos en este trabajo, a partir de la evidencia considerada previamente en nuestros casos de análisis (la Estancia Peñas Chicas y los cuatro corredores de tráfico), que las trayectorias históricas de una lógica territorial pastoril y trashumante, desde el mundo material, persisten (sensu Silliman, 2009) aún en contextos de modernidad.

En relación a las diferentes estrategias de la población puneña ante el Estado, Martinez y Ataliva (2020) sugieren que las mujeres y los hombres de Antofagasta acumularon experiencias con las sucesivas administraciones que les permitirán -a partir de la anexión a la Argentina- contar con capitales específicos para posicionarse con cierto margen de maniobra y entablar las "nuevas" relaciones con el Estado al que fueron integrados. Proponen los autores que estas experiencias se materializan en los grabados en la Estancia Peńas Chicas, los cuales son interpretados como 
dispositivo identitario generado por una familia a los fines de enfatizar la apropiación de este sector de la quebrada de Las Pitas frente a sus contemporáneos y, también, frente al Estado. Para ello, la familia Morales genera una respuesta original: emplea una herramienta clave en la comunicación administrativa y plenamente identificada con el Estado: inscribirá -o escribirá- su presencia en las peñas con los signos alfabéticos propios de los haceres burocráticos (Martinez y Ataliva, 2020).

La relación de los puneños con el paisaje responde a un estilo de vida íntimamente ligado a los ciclos de la hacienda: una movilidad anual a nivel local, con el establecimiento y mantenimiento de puestos de pastoreo alejados de la casa familiar, los cuales eran utilizados estacionalmente. Lo anterior combinado con una movilidad a nivel regional, caracterizada por la realización de viajes a mediana y larga distancia, en los cuales se intercambiaban los productos y recursos obtenidos durante el ańo por recursos no disponibles en la puna, productos de origen industrial o bien, dinero en metálico. En estos viajes se generaban y mantenían vínculos familiares, de compadrazgo, comerciales y de confianza con la gente de localidades alejadas, asegurando así la reproducción y continuidad de este sistema (García et al., 2002; Molina Otárola, 2010; Zamora, 2019).

Este recorrer se expresa, en el mundo material, tanto en los senderos que recorren el paisaje como en las estructuras demarcatorias, rituales y de reparo. Los materiales recuperados dan cuenta de actividades pastoriles o relacionadas con el manejo de hacienda, como las cuerdas, las piezas textiles reconfiguradas para envolver, herraduras y un cencerro confeccionado con una lata de conservas, alambre y un fragmento de herradura. El consumo de bienes de origen artesanal como el aguardiente (que era envasado en botellas de vidrio fabricadas originalmente para aceite comestible) y de origen industrial como la ginebra, así como los enlatados, parece haber sido frecuente durante la realización de actividades internodales, ya sean de escala local o relacionadas con viajes de larga distancia. Según entrevistas sostenidas con pastores y pastoras puneńas, el pernocte durante los momentos de actividad internodal se realizaba en lugares determinados del paisaje, caracterizados por lo general por contar con agua potable para humanos y hacienda y reparo de los fuertes vientos nocturnos (Zamora, 2019). El sitio Los Negros-Área de Campamentos probablemente funcionó como un lugar de pernocte transitorio, eventual, dada la ausencia de agua y la cercanía relativa con el nodo del pueblo de Antofagasta de la Sierra.

Puede interpretarse que la actividad arriera, caravanera y pastoril funcionaba de forma no centralizada durante el intervalo cronológico abordado en este trabajo (mediados del siglo XIX a mediados del XX), sino que probablemente el nodo de un núcleo familiar puneño en particular era su residencia permanente, ya sea que esta se encontrara en Antofagasta de la Sierra, en El Peńón, en Antofalla o en Carachipampa. Es desde ese nodo (entre los que incluimos la Estancia Peñas Chicas) que las redes y las rutas individuales o familiares se generaban, y es en relación a ese nodo que las actividades económicas internodales se trazaban (los lugares de caza, de recolección de minerales, de acampado durante los viajes). De esto puede inferirse que, si bien el peso de Antofagasta de la Sierra como centro poblacional en la región fue de tipo administrativo/estatal (dada la presencia histórica del Estado en cuanto a Juez de Paz, Delegados, Parroquia, Destacamentos de las fuerzas de seguridad), este no fue tan significativo en la escala de la economía familiar, enfocada en lo pastoril y con un carácter autosuficiente (García y Rolandi, 2003; Kupersmit, 2009; Molina Otárola, 2010).

Desde el espacio doméstico, la EPCh, se observa una combinación de tecnofacturas de origen prehispánico -fragmentos de cerámica, material lítico, cordeles y tejidos artesanales- con las 
incorporadas a partir de la colonización española -fragmentos de latas, vidrios, cerámica histórica, herradura, utensilios de metal, restos de papel-. No se suprime ni se reemplaza la evidencia vinculada a lo cotidiano con aquella de carácter ancestral. Es una forma de dejar plasmado un acto de residencia (sensu Silliman, 2001) a partir de la articulación y combinación de lo preexistente con lo nuevo, generando modos de residir propios (Martinez, 2020a).

La evidencia material hallada en los contextos de excavación nos habla de diferentes usos del espacio de los recintos, y remite a prácticas vinculadas a la vida cotidiana, como el consumo de alimentos, piezas textiles que formaron parte de la vestimenta, prácticas productivas, como la elaboración de cordeles y tejido, y tinción para un consumo familiar. También se registran evidencias significativas como las plataformas rectangulares macizas y cama de haces de cortadera entrelazados, que nos indica un espacio de pernocte. Asimismo, se observan espacios reutilizados que se convierten en lugar de descarte y residuos y evidencias de prácticas de entretenimiento, como el juego de la taba; prácticas de interacción y de viajes no solo reflejados en el consumo de bienes alóctonos, sino también mediante la presencia de lo que, inferimos, corresponde a una maleta utilizada en los viajes. Todo este conjunto de materialidades da cuenta de la vida doméstica de una familia, de la organización del espacio intramuros en una casa puneña, y de los espacios internodales en contexto republicano.

La reafirmación de la territorialidad que se da en la larga duración en contexto colonial y republicano se constituye como eje para la reproducción de la memoria social. Es una lógica que continúa incluso después de la Colonia hasta el Período Republicano, porque el vínculo con el entorno, con la tierra, con los animales, con las plantas y los seres inanimados tiene una conexión más profunda que parcelar tierras para habitar un solo lugar (Martinez, 2020b).

Dicha lógica andina es lo que Sillar (2009) denomina identidad social de las cosas y de los lugares en el mundo andino. El autor señala que hay un involucramiento social en el mundo que se vincula con la creatividad de moverse entre, o combinar, la cultura material y la relación social con ella. En este sentido, si de involucramiento hablamos, nos parece significativo referirnos a "la casa", pero como un referente material de ver el mundo, en diferentes emplazamientos y combinando lo sagrado, lo doméstico y lo productivo (Martinez, 2020a).

Sillar (2009) sostiene la idea de consumo mutuo en donde las personas, los lugares y cosas animadas de los Andes se alimentan y crían entre sí. Es decir, existe un compromiso recíproco en la relación de lo humano con lo inanimado. Esta cosmovisión atraviesa las formas de residir: en las prácticas, en los espacios, los animales, el entorno natural, en los viajes y la veneración a deidades andinas.

A partir de la evidencia analizada en estos casos de análisis particulares en la puna de Atacama - una unidad residencial rural de fines del siglo XIX y principios del siglo XX y los corredores de tráfico-, creemos que la perduración de ciertas prácticas sociales, íntimamente conectadas con las ontologías andinas, fortalece los lazos familiares, comunitarios e intercomunitarios, y a su vez reivindica la reproducción de la memoria social de las familias puneñas (Martinez, 2020a). En este sentido, los espacios de autonomía de un grupo fortalecen dichos lazos de manera tal que se convierten en una toma de posición y una forma de negociación en contextos de relaciones asimétricas (Hutson, 2002). Con todo lo anterior, planteamos que este modo de residir pastoril trashumante de la unidad familiar puneńa, con una fuerte tradición prehispánica, les permitió "moverse" con cierta autonomía en una lógica propia ante los nuevos escenarios sociopolíticos. 


\section{Agradecimientos}

A Antofagasta de la Sierra y a su gente. A la familia Morales, por permitirnos trabajar en la estancia habitada por su abuelo y bisabuelos. A los miembros del equipo de investigación de ANS-UNT/CONICET, que colaboraron en el análisis de las distintas evidencias aquí presentadas. A Pilar Babot, por su lectura, valiosos comentarios y sugerencias a este manuscrito. Sin embargo, es de nuestra entera responsabilidad lo aquí expuesto. A Roy Casañas Rígoli por el trabajo de fotogrametría de la estancia. Este trabajo se realizó en el marco de los Proyectos PIP 577, dirigido por C. Aschero; PIUNT 26/G503, dirigido por M. P. Babot y FONCYT-PICT 2015-2067, dirigido por A. Martel.

\section{Referencias citadas}

Aguirre, G. (2019). Análisis antracológico en el sitio Estancia Peñas Chicas, Antofagasta de la Sierra (Catamarca) (Informe técnico inédito). Universidad Nacional de Tucumán, Tucumán, Argentina.

Ananchev, G. (2012). Perceptions of landscapes of Movement: Phenomenology and the Archaeology of Roman Roads. Milwaukee, WY: University of Wisconsin.

Araneda, Y. (2017). Habitar un paisaje de movimiento. Arqueología de la ruta Catarpe-Calama en tiempos de las remesas, Región de Antofagasta (1870-1940). Tesis de Grado. Universidad de Chile, Santiago, Chile.

Arnold, D. Y. (1998). Hacia un Orden Andino de las Cosas. La Paz: Hisbol.

Arnold, D. Y. (2000). "Convertirse en persona”. El tejido: la terminología aymara de un cuerpo textil. En Solanilla Demestre, V. (Ed.). Tejiendo sueños en el Cono Sur: Textiles Andinos: Pasado, Presente y Futuro (pp. 9-28). Barcelona: Grupos de Estudios Precolombinos (GEP), Departamento de Arte de la Universidad Autónoma de Barcelona.

Aschero, C. A. (1994). Reflexiones desde el Arcaico Tardío (6000-3000 AP). Rumitacana. Revista de Antropologia, 1, 13-17.

Aschero, C. A. (1999). El Arte Rupestre del Desierto Puneño y el Noroeste Argentino. En Arte Rupestre en los Andes de Capricornio (pp. 97-135). Santiago: Museo Chileno de Arte Precolombino y Banco de Santiago.

Aschero, C. A. (2000). El poblamiento del territorio. En Tarragó, M. (Ed.). Nueva Historia Argentina 1, Los pueblos originarios y la conquista (pp. 17-59). Buenos Aires: Sudamericana.

Aschero, C. A. (2005). Investigaciones arqueológicas en el área del curso medio del río Las Pitas y curso alto del río Miriguaca (Informe elevado a la Dirección de Antropología de la Provincia de Catamarca). Catamarca, Argentina.

Aschero, C. A., Escola, P. S., Hocsman, S. y Martínez, J. (2002-04). Recursos líticos en la escala microrregional Antofagasta de la Sierra, 1983-2001. Arqueología, (12), 9-36.

Aschero, C. A. y Hocsman, S. (2011). Arqueología de las ocupaciones cazadoras recolectoras de fines del Holoceno Medio de Antofagasta de la Sierra (Puna Meridional Argentina). Chungara. Revista de Antropología Chilena, 43(Número especial 1), 393-411.

Babot, M. P. (2006). El papel de la molienda en la transición hacia la producción agropastoril: Un análisis desde la puna meridional argentina. Estudios Atacameños. Arqueología y Antropología Surandinas, 32, 75-92. 
Babot, M. P., Aschero, C. A., Hocsman, S., Haros, M. C., González Baroni, L. y Urquiza, S. (2006). Ocupaciones agropastoriles en los sectores intermedios de Antofagasta de la Sierra (Catamarca): un análisis desde Punta de la Peña 9.I. Comechingonia, 9, 57-78.

Babot, M. P., Hocsman, S., González Baroni, L., Aguirre, M. G., Urquiza, S., Haros, M. C. y Colaneri , M. G. (2009). Dinámicas de formación y transformación de un entierro en el desierto puneño (Antofagasta de la Sierra, Puna Meridional Argentina). Intersecciones en Antropología, 10(2), 183-201.

Benedetti, A. (2002) Los efectos de la inclusión. Transformaciones territoriales y reorganización de la red de lugares poblados en las tierras altas de Jujuy durante el siglo XX. En McCants, A. (Presidencia ejecutiva), XIII World Congress of the International Economic History Association. Buenos Aires, Argentina.

Benedetti, A. (2005). Un territorio andino para un pais pampeano. Geografía histórica del territorio de los Andes 1900-1943. Tesis doctoral. Universidad de Buenos Aires, Buenos Aires, Argentina.

Berenguer, R. y Pimentel, G. (2017). Introducción al estudio de los espacios internodales y su aporte a la historia, naturaleza y dinámica de las ocupaciones humanas en zonas áridas. Estudios Atacameños. Arqueologia y Antropologia Surandinas, 56, 3-11.

Boero, J. (1916). Geografía de la Nación Argentina (adaptada a los programas de Enseñanza Secundaria, Normal y Especial). Buenos Aires: Ángel Estrada.

Carreras, J. (2017). Fogones, hornos, cocinas y fuegueros de Cusi Cusi (puna de Jujuy). Análisis etnoarqueológico de las prácticas domésticas pastoriles vinculadas a las estructuras de combustión. Arqueología, 23(1), 129-130.

Cohen, M. L. (2005). Entre guano y arena... Ocupaciones recurrentes: Un caso de estudio en el sitio Punta de la Peña 9 III, Antofagasta de la Sierra, Catamarca. Tesis de Grado en Arqueología. Universidad Nacional de Tucumán, Tucumán, Argentina.

Cohen, M. L. (2010). Prácticas sociales, estrategias de visibilidad y construcción de la cartografía social durante el lapso de ca 1000-500 años AP, en Antofagasta de la Sierra, Catamarca-Perspectivas desde el sitio Peñas Coloradas 3 cumbre. Tesis doctoral. Universidad de Buenos Aires, Buenos Aires, Argentina.

Cohen, M. L. (2014). Miradas desde y hacia los lugares de poder. Antofagasta de la Sierra entre 1000 y 1500 años D.C. Arqueología, 20(1), 47-72.

Cohen, M. L. y Martinez, M. S. (2020). Atados a la tierra, una forma de perdurar a través de rituales pastoriles en Antofagasta de la Sierra. Chungara. Revista de Antropología Chilena. En prensa.

Conti, V. (2003). El norte argentino y Atacama. Flujos mercantiles, producción y mercados en el siglo XIX. En Benedetti, A. (Comp.). Puna de Atacama: sociedad, economía y frontera (pp. 21-52). Córdoba, Argentina: Alción Editora.

Conti, V. (2006). La ruta de los arrieros y el salitre. Las rutas del capricornio andino, 95-103.

Cruz, P. (2014). Desde el diabólico mundo de los gentiles. Lecturas sobre un pasado muy presente en el espacio alto-andino de Potosí y Chuquisaca (Bolivia). Revista Española de Antropología Americana, 44(1), 217-234.

Delgado, F. y Göbel, B. (2003). Departamento de Susques: la historia olvidada de la Puna de Atacama. En Benedetti, A. (Comp.). Puna de Atacama: sociedad, economia y frontera (pp. 81-104). Córdoba, Argentina: Alción Editora. 
Escola, P. (2002). Caza y pastoralismo: un reaseguro para la subsistencia. Relaciones de la Sociedad Argentina de Antropología, XXVII, 233-245.

Flores Ochoa, J. A. y Kobayashi, Y. (Eds.). (2000). Pastoreo altoandino. Realidad, sacralidad y posibilidades. La Paz: Plural Editores.y las prácticas. Chungara. Revista de Antropología Chilena, 50(1), 51- 70.

García, S., Rolandi, D., López, M. y Valeri, P. (2002). Viajes comerciales de intercambio en el Departamento de Antofagasta de la Sierra, Puna meridional argentina: pasado y presente. Revista Redes. Recuperado de: http:// http://revista-redes.rediris.es/html-vol2/vol2_5.htm

García, S. y Rolandi, D. (2003). Antofagasta de la Sierra, provincia de Catamarca: Su historia en los documentos y la tradición oral. En Benedetti, A. (Comp.). Puna de Atacama: sociedad, economía y frontera (pp. 137-198). Córdoba, Argentina: Alción Editora.

García, S. y Rolandi, D. (Comp.). (2004). ¿Quiénes somos? Entretejiendo identidades en la puna catamarqueña. Buenos Aires: Asociación Amigos del Instituto Nacional de Antropología - Ediciones del Tridente.

Göbel, B. (2002). La arquitectura del pastoreo: uso del espacio y sistema de asentamientos en la Puna de Atacama (Susques). Estudios Atacameños. Arqueología y Antropología Surandinas, 23, 53-76.

González Baroni, L. (2013). Contextos funerarios y vida cotidiana en Antofagasta de la Sierra, Catamarca. Un enfoque desde la bioantropología, el emplazamiento y dinámica de los entierros (ca. 1500-1000 años AP). Tesis de Grado en Arqueología. Universidad Nacional de Tucumán, Tucumán, Argentina.

González Baroni, L. (2014). Un entierro secundario múltiple del primer milenio A.D. en la Puna Meridional (Antofagasta de la Sierra, Catamarca, Argentina). En Luna, L., Aranda, C. y Suby, J. (Eds). Avances Recientes de la Bioarqueología Latinoamericana (pp. 169-186). Buenos Aires: GIB.

Haber, A. (1999) Caspinchango, la ruptura metafísica y la cuestión colonial en la arqueología sudamericana: el caso del noroeste argentino. Revista do Museu de Arqueología y Etnología. Anais da I Reuniao Internacional de Teoria Arqueológica na América do Sul, 3, 129-141.

Haggett, P. (1976). Locational Analysis in Human Geography. London: Edward Arnold.

Hocsman, S. (2006). Producción lítica, variabilidad y cambio en Antofagasta de la Sierra - ca. 5500-1500 AP. Tesis doctoral en Cs. Naturales. Universidad Nacional de La Plata, La Plata, Argentina.

Hocsman, S. (2007). Aportes del sitio Peñas Chicas 1.3 a la arqueología defines del Holoceno Medio de Antofagasta de la Sierra (Catamarca, Argentina). Cazadores-recolectores del Cono Sur. Revista de Arqueologia, 2, 167-189.

Hocsman, S. y Babot, M. P. (2018). La transición de cazadores-recolectores a sociedades agropastoriles en Antofagasta de la Sierra (Puna de Catamarca, Argentina): Perspectivas desde la agencia

Hutson, S. R. (2002). Built space and bad subjects: Domination and resistance at Monte Albán, Oaxaca, Mexico. Journal of Social Archaeology, 2(1), 53-80.

Kuperszmit, N. (2009). Relaciones politicas, sociales y económicas de un pueblo de pastores. Antofagasta de la Sierra, Territorio Nacional de Los Andes. Tesis de Grado. Universidad de Buenos Aires, Buenos Aires, Argentina. 
López Campeny, S. M. L. (2001). Actividades domésticas y organización del espacio intrasitio. El sitio Punta de la Peña 9 (Antofagasta de la Sierra, Prov. de Catamarca). Tesis de Grado en Arqueología. Universidad Nacional de Tucumán, Tucumán, Argentina.

López Campeny, S. M. L. (2009). Asentamiento, Redes Sociales, Memoria e Identidad Primer milenio de la era Antofagasta de la Sierra, Catamarca. Tesis doctoral en Ciencias Naturales. Universidad Nacional de La Plata, La Plata, Argentina.

López Campeny, S. M. L. (2014). The agency of textile technology in some archaeological ritual contexts of Northwest Argentina. Journal of Anthropology and Archaeology, 2, 39-75.

López Campeny, S. M. L. y Martel, A. (2014). La vestimenta del poder. Comparando los registros textil y rupestre en el noroeste de Argentina (siglos XIII a XV). Relaciones de la Sociedad Argentina de Antropologia, XXXIX, 21-55.

Martel, A. (2010). Arte rupestre de pastores y caravaneros, estudio contextual de las representaciones rupestres durante el periodo tardio (900 d.C. - 1480 d.C.) en el Noroeste Argentino. Tesis doctoral en Arqueología. Universidad de Buenos Aires, Buenos Aires, Argentina.

Martel, A. (2014). Aguas Calientes. Evidencias directas de tráfico caravanero entre la Puna meridional y el Valle Calchaquí. Estudios Sociales del NOA, 13, 103-124.

Martel, A. y Aschero, C. A. (2007). Pastores en acción: imposición iconográfica vs. autonomía temática. En Nielsen, A. E., Rivolta, M. C., Seldes, V., Vázquez, M. y Mercolli, P. (Eds.). Producción y Circulación Prehispánicas de Bienes en el Sur Andino. Colección Historia Social precolombina. Tomo 2 (pp. 329-349). Córdoba, Argentina: Editorial Brujas.

Martel, A. R., Zamora, D. y Lépori, M. (2017). Tráfico y movilidad caravanera en la Puna catamarqueña. Una mirada internodal. Estudios Atacameños. Arqueología y Antropología Surandinas, 56, 197-223.

Martínez, J. (2012). Evidence of early human burials in the Southern Argentinian Puna. En Miotti, L., Salemme, M., Flegenheimer, N. y Goebel, T. (Eds). Southbound: Late Pleistocene Peopling of Latin America (pp. 75-78). Texas, TX: Center for the Study of First Americans Department of Anthropology Texas A\&M University.

Martínez, J. (2014). Contributions to the knowledge of natural history and archaeology of hunter-gatherers of Antofagasta de la Sierra (Southern Argentinian Puna): the case of Peńas de las Trampas 1.1. En Pintar, E. (Ed.). Hunter-gatherers from a high-altitude desert. People of the Salt Puna (northwest Argentina) (pp. 1-23). Oxford: Archaeopress.

Martinez, M. S. (2012). Prácticas Textiles resignificadas en Contextos de Transformaciones en Antofagasta de la Sierra (Provincia de Catamarca-Argentina). Integrando materialidad del pasado y la oralidad del presente. Tesis de Grado. Universidad Nacional de Tucumán, Tucumán, Argentina.

Martinez, M. S. (2017). Tecnología textil histórica en contextos rituales prehispánicos. Antofagasta de la Sierra, Catamarca-Noroeste Argentino. Comechingonia, 21(2), 351-378.

Martinez, M. S. (2020a). Residir en contexto republicano en Antofagasta de la Sierra, Puna meridional argentina. Un abordaje desde la materialidad textil. Arqueología. Arqueología, 26(2), 59-83. 
Martinez, M. S. (2020b). Reproducción social, material y simbólica de las prácticas textiles en contexto colonial y republicano. Antofagasta de la Sierra, Puna meridional argentina. Tesis doctoral. Universidad de Buenos Aires, Buenos Aires, Argentina.

Martinez, M. S. y Ataliva, V. (2020). Los grabados históricos en las Peńas Chicas. La anexión de la Puna de Atacama desde una estancia de Antofagasta de la Sierra (Catamarca, Argentina). Intersecciones en Antropología, 21(1), 99-112.

Memmott, M. (2015). What CAN this be? A practical workshop on tin can identification and analysis. En Giambastiani, M. (Presidencia), Nevada Archaeological Association 44th Annual Meeting Wendover, Nevada, Estados Unidos de América.

Molina Otárola, R. J. M. (2010). Collas y Atacameños en el desierto y la puna de atacama y el valle de Fiambalá: sus relaciones transfronterizas. Tesis doctoral en Antropología. Universidad de Tarapacá, Arica y Universidad Católica del Norte, Antofagasta, Chile.

Nielsen, A. E. (2000). Andean Caravans: An Ethnoarchaeology. Tesis doctoral. University of Arizona, Tucson, United States.

Nielsen, A. E. (2006). Estudios internodales e interacción interregional en los Andes Circumpuneños: Teoría, método y ejemplos de aplicación. En Lechtman, H. (Ed.). Esferas de interacción prehistóricas y fronteras nacionales modernas en los Andes Sur Centrales (pp. 29-62). Lima: Instituto de Estudios Peruanos e Institute of Andean Research.

Nielsen, A. E. (2017). Actualidad y potencial de la Arqueología internodal surandina. Estudios Atacameños. Arqueologia y Antropologia Surandinas, 56, 299-317.

Olivera, D. E. (1992). Tecnología y estrategias de adaptación en el Formativo (Agroalfarero Temprano) de la Puna Meridional Argentina. Un caso de estudio: Antofagasta de la Sierra (Pcia. de Catamarca, R.A.). Tesis doctoral en Cs. N. Universidad Nacional de la Plata, La Plata, Argentina.

Paoli, H. (2011). Cuenca Cerrada de la Puna, Subcuenca Carachi Pampa - Incahuasi. (Informe presentado ante el Instituto Nacional de Tecnología Agropecuaria (INTA), Salta, Argentina.

Patané Aráoz, C. J. (2018). Estudio y evaluación de impacto arqueológico seguimiento y control arqueológico. (Informe de Evaluación de Impacto Minera Esperanza S.A.). Antofagasta de la Sierra, Catamarca, Argentina.

Pimentel, G. (2013). Redes Viales Prehispánicas en el Desierto de Atacama. Viajeros, Movilidad e Intercambio. Tesis doctoral. Universidad Católica del Norte y Universidad de Tarapacá, San Pedro de Atacama, Chile.

Pintar, E. (2014). Continuidades e hiatus ocupacionales durante el Holoceno Medio en el borde oriental de la Puna Salada, Antofagasta de la Sierra, Argentina. Chungara. Revista de Antropología Chilena, 46(1), 51-71.

Puente, V. (2018). Análisis cualitativo de tortero de cerámica, Estancia Peñas Chicas. (Informe técnico inédito). Universidad Nacional de Tucumán, Tucumán, Argentina.

Quiroga, L. (2014). Paisajes de rebeldía: Reproducción, identidades y resistencia en la serranía de Londres (Gobernación del Tucumán) Siglos XVI y XVII. Revista de Arqueología Americana, 32, 151-175 
Quiroga, L. (2015, julio/diciembre). Del páramo a la puna. Textos y contextos arqueológicos para una descripción del paisaje altoandino en la gobernación del Tucumán. Corpus, 5(2). Recuperado de: http:// journals.openedition.org/corpusarchivos/1516; DOI: 10.4000/ corpusarchivos.1516

Quiroga, L. y Cohen, M. L. (2007). (Ms.) Múltiples espacios... una misma peña. Diseño arquitectónico y emplazamiento en sitios tardíos. Punta de la Peña. Antofagasta de la Sierra, Catamarca. Ponencia presentada en el XVI Congreso Nacional de Arqueología, Jujuy. Octubre 2007.

Reboratti, C. (2005). Situación ambiental en las ecorregiones puna y altos andes. En Brown, A., Martínez Ortiz, U., Acerbi, M. y Corcuera, J. (Eds.). La situación ambiental argentina (pp. 28-31). Buenos Aires: Fundación Vida Silvestre Argentina.

Ricoeur, P. (2000). La memoria, la historia y el olvido. Madrid: Trotta.

Rock, J. (1993). Can Chronology. California, CA: Facsimile by Coyote Press Salinas.

Rodríguez, F. (2006). El uso de las plantas y el espacio doméstico en la Puna meridional argentina a comienzos del Holoceno Tardío. Sitio arqueológico Punta de la Peńa 4, capa 3x/y. Chungara. Revista de Antropologia Chilena, 38(2), 253-267.

Sanhueza, C. (2011). Tráfico caravanero, arriería y trajines en Atacama colonial. Síntesis y discusiones sobre un proceso de adaptación andina. Temporalidad, interacción y dinamismo cultural. En Hubert, A.,. González, J. A. y Pereira, M. (Eds.). La búsqueda del Hombre. Homenaje al Profesor Lautaro Núñez Atencio (pp. 289-321). Antofagasta, Chile: Ediciones Universitarias Universidad Católica del Norte.

Santoro, C. M. y Núñez, L. (1987). Hunters of the Dry Puna and the Salt Puna in Northern Chile. Andean Past, 1, 57-109.

Sillar, B. (2009). The social agency of things? Animism and materiality in the Andes. Cambridge Archaeological Journal, 19, 367-377.

Silliman, S. (2001). Agency, practical politics and the archaeology of culture contact. Journal of social archaeology, 1(2), 190-209.

Silliman, S. (2009). Change and continuity, practice and memory: Native American persistence in colonial New England. American Antiquity, 74(2), 211-230.

Tilley, C. (1994). A Phenomenology of Landscape: Places, Paths and Monuments. Oxford: Berg Publishers.

Tomasi, J. (2012). Lo cotidiano, lo social y lo ritual en la práctica del construir. Aproximaciones desde la arquitectura puneña (Susques, provincia de Jujuy, Argentina). Revista de estudios sobre Patrimonio Cultural, 25, 8-21.

Urquiza, S., Romano, A. S. y López Campeny, S. M. L. (2013). Historia ocupacional y prácticas sociales: Un análisis arqueofaunístico contextual. Sitio Piedra Horadada 2, Antofagasta de la Sierra, Catamarca, Argentina. En Izeta, A. y Mengoni Goñalons, G. De la Puna a las Sierras: Avances y Perspectivas en Zooarqueología Andina (pp. 121-144). Oxford: Archaeopress.

Urquiza, S. y Aschero, C. (2014). Economía animal a lo largo del Holoceno en la Puna Austral Argentina: Alero Punta de la Peña 4. Cuadernos del Instituto Nacional de Antropología y Pensamiento Latinoamericano, Series Especiales 2(1), 86-112. 
Arqueología republicana en Antofagasta de la Sierra, puna de Atacama: un abordaje desde los espacios...

Yacobaccio, H., Madero, C. M. y Malmierca, M. P. (1998). Etnoarqueología de pastores surandinos. En Northwestern Argentine Rock Art. In Valcamonica Symposium '93 (pp. 1-15). Italia: Centro Camuno di Studi Preistorici.

Zamora, D. (2019). La Memoria y los Senderos: Investigación internodal de las vias de circulación en las áreas de Antofagasta de la Sierra y El Peñón, entre mediados del S. XIX y finales del S. XX. Tesis de Grado. Universidad Nacional de Tucumán, Tucumán, Argentina. 